\title{
Investigating the relationship between indoor environment and workplace productivity in naturally and mechanically-ventilated office environments
}

\author{
Professor Rajat Gupta BArch, MSc, PhD, FRSA \\ Mr Alastair Howard BSc, MSc \\ Dr Sahar Zahiri BArch MA PhD
}

Low Carbon Building Research Group, Oxford Institute for Sustainable Development, School of Architecture, Oxford Brookes University, Oxford, UK

rgupta@brookes.ac.uk

\begin{abstract}
This paper uses a case study-based approach to empirically investigate the relationship between indoor environment and workplace productivity in two contrasting office environments: one naturally-ventilated (NV), the other mechanically-ventilated (MV). Environmental parameters were continuously monitored over 19 months. Transverse and longitudinal surveys recorded occupants' perception of their working environment and self-reported productivity, while performance tasks (numerical and proofreading) measured cognitive capability as proxy for measured productivity.

Indoor temperatures and $\mathrm{CO}_{2}$ concentrations were found to be higher and more variable in the naturally-ventilated office. However, the correlation between occupant perception of their indoor environment and perceived productivity was stronger in the MV office. Occupants of the NV office were found to be more tolerant of their environment than their counterparts in the MV office. Task performance was affected by indoor environmental conditions such as indoor temperature and $\mathrm{CO}_{2}$ concentration. Interestingly in the NV office, the median scores were up to $12 \%$ higher for tests conducted at $\mathrm{CO}_{2}$ concentrations $<1400 \mathrm{ppm}$, compared to those conducted above 1400 ppm, whereas in the MV office this threshold was only 1000 ppm.
\end{abstract}

Keywords: Productivity, office, indoor environment, health, comfort

\section{Practical application}

The study showed that higher concentrations of $\mathrm{CO}_{2}$ were associated with lower task scores and longer task durations, reinforcing the need for good levels of ventilation in workspaces. It was found that occupants in NV workspaces were able to adapt to a broader range of environmental conditions. Therefore, controlling the indoor environment within narrow ranges (expending significant amounts of energy in the process) may not always be necessary to improve comfort and productivity. On the other hand, controlling indoor environment within a narrow range - as is common in MV workspaces - may be counterproductive, creating occupants who are less tolerant of small changes in their environmental conditions. The study also demonstrates occupant surveys can provide useful feedback on perceived comfort and productivity at relatively low cost. Insights from such surveys can be used to improve indoor environment in workspaces. 


\section{Introduction}

Workplace productivity, a measure of how well a business uses its resources to achieve a goal (1), has been identified by the Office for National Statistics (ONS) as being a concern for the UK. In 2016, output per hour worked was $15 \%$ lower than the average for the other $\mathrm{G} 7$ nations (2), the group of seven nations with the largest advanced economies in the world (consisting of the UK, USA, Canada, France, Germany, Italy and Japan).

This productivity gap has been attributed to economic factors (e.g. poor investment, inefficient processes), but also human factors such as stress, health and comfort. It has been estimated that sickness and poor health cost UK employers more than $£ 9$ billion a year through absenteeism (3). Costs associated with presenteeism, the practise of turning up for work whilst unwell, could be even greater as this can not only result in a less productive day, but also risk the spread of infection to colleagues. Research has suggested that a $2-3 \%$ increase in productivity could be achieved by improving the working environment (1). This may not appear to be much, but as staff costs make up the vast majority of a business's expenses (4), there is a clear financial incentive to improve productivity, even at the expense of potentially increasing energy use in order to achieve and maintain a more favourable working environment.

Certain indoor environmental parameters have been shown to influence workers' productivity in office buildings (5). Identifying conditions which may have a negative effect on productivity are inherently easier to define than those conditions which can provide optimal productivity. Most intervention and office-based studies investigating this link between improved indoor environment and increased productivity have focussed on individual indoor environment elements, e.g. temperature or ventilation rates (6-8). In real office settings, however, the indoor environment is more dynamic, with occupants experiencing a range of temperatures, relative humidity $(\mathrm{RH})$ levels, $\mathrm{CO}_{2}$ concentrations, ventilation rates and air pollutants throughout a typical working day.

There are additional challenges to interpreting data collected in real-world office environments, such as isolating the effects of temperature from air quality. Office design, layout, and biophilia have also been shown to influence productivity and interact with indoor environment variables controlled by building services (9). In product-based workspaces, productivity can be easily defined as the number of units produced divided by the number of man-hours used in production. Productivity is inherently more difficult to define in the context of service-based offices, where the output is more qualitative than quantitative (10).

Nevertheless, it is evident that the link between indoor environment and productivity (whether perceived or measured) in office environments is becoming increasingly recognised. The research presented in this paper sought to empirically quantify the link between indoor environment, thermal comfort, and perceived and measured productivity. Two contrasting case-study buildings were studied: an older, mixed-mode office building in central London and a more modern, mechanically-ventilated office building in the south of England. The buildings were compared and contrasted in how occupants responded to their indoor environment, and any subsequent links to their performance and productivity. The research was part of an EPSRC/Innovate UK funded Whole Life Performance Plus (WLP+) project that sought to develop a dynamic 
approach for improving workplace productivity by optimising the indoor environmental conditions.

\section{Indoor environment and workplace productivity: evidence to date}

Studies which have investigated the relationship between indoor environment and occupant productivity/health/comfort have found that negative factors (such as high temperatures, $\mathrm{CO}_{2}$ concentrations or noise) were more easily identifiable than positive factors (i.e. those conditions that enable productivity to increase or health and comfort to improve). Further studies have sought to develop the understanding of these relationships. For example, in naturally ventilated buildings, ASHRAE defines the comfort indoor temperature as being dependent on outdoor temperature, with a $5{ }^{\circ} \mathrm{C}$ and $7{ }^{\circ} \mathrm{C}$ comfort zone band for $90 \%$ and $80 \%$ acceptability respectively (11). Within this range, it is implied that there is no direct risk to occupants' health and comfort.Error! Reference source not found.

Several studies have found a relationship between indoor temperature and workers' productivity: Task errors increasing by $56 \%$ at high temperatures compared to low temperatures (12); performance decreasing at higher temperatures (13); almost 40\% of the variation in task performance accounted for by temperature variation (14). Although Fang et al. found no significant effect of temperature (with set points of 20, 23 and $26^{\circ} \mathrm{C}$ ) on performance (15), participants reported an increase in sick building syndrome (SBS) symptoms and difficulty thinking at higher temperatures. Liu et al.'s occupant surveys and environmental monitoring were conducted over a whole year (16), observing that occupants' adaptive responses were strongly driven by ambient thermal stimuli: The variations in results, seasonally, daily and even hourly, indicated the role of adaptation in occupants' perception of their conditions and their own productivity. Combining results from a climate chamber intervention and observational surveys in a real-world office, Tanabe et al. (17) found that measured air temperature correlated poorly with perceived performance, whereas thermal comfort correlated much more strongly with perceived performance (17). An intervention study in a climate chamber in China found that when temperatures moved further from the 'neutral' thermal comfort range, participants rated their thermal comfort to be less satisfactory, but their 'comfort expectation' for other IEQ factors was weakened (18). In this experiment, only air temperature was varied, with other IEQ factors remaining constant. However, when temperatures were perceived to be cooler or warmer than neutral, participants were more satisfied with other IEQ factors including indoor air quality, lighting and noise.

Of particular interest in several studies (including (13) and (19)) was the discrepancy between the temperature range for optimum thermal comfort and that for optimum productivity - i.e. the temperature range identified as thermally comfortable was different to the range that produced the best productivity. Furthermore, an intervention study in Germany found that variations in temperature resulted in significant differences in performance between male and female participants: In verbal and numerical tasks, female performance improved and male performance worsened at higher temperatures (20). This poses an additional challenge to building managers seeking to find the optimum thermal environment for their mixed-gender workforce.

As well as temperature, several studies have found a relationship between air quality (often measured as $\mathrm{CO}_{2}$ concentration or ventilation rates) and worker performance. 
Studies investigating worker performance at different ventilation rates found that higher ventilation rates correlated with a more productive workforce: Increasing ventilation rates from 5 to $10 \mathrm{l} / \mathrm{s} / \mathrm{p}$ corresponded to an $11 \%$ reduction in call talk time (21); for every doubling of ventilation rate from 3-30 l/s/p, performance increased by $1.7 \%$ (22); increasing ventilation rates from 5 to $20 \mathrm{l} / \mathrm{s} / \mathrm{p}$ corresponded to a $5 \%$ improvement in accuracy of calculation tasks (8); increased ventilation rates corresponded to an $18 \%$ increase in cognitive function scores (19). Studies which focussed on $\mathrm{CO}_{2}$ concentrations (often used as a proxy for ventilation rate) came to similar conclusions: when $\mathrm{CO}_{2}$ concentrations increased from $600 \mathrm{ppm}$ to $1000 \mathrm{ppm}$ and $2500 \mathrm{ppm}$, there were moderate to large decreases in decision making performance (23); participants exposed to $\mathrm{CO}_{2}$ concentrations up to $4000 \mathrm{ppm}$ had significantly more misspelled words in a typing task (24); and as $\mathrm{CO}_{2}$ concentration increased, call handling times in a call centre increased (25).

In addition to these IEQ parameters, other factors have been found to have a role in influencing occupant comfort, health and productivity. The level of control workers have (or perceive that they have) on their localised indoor environmental conditions has been found to have a relationship with perceived levels of comfort. An observational field study across eighteen office buildings in Switzerland found that occupant's perceived comfort was improved when they were able to open windows themselves and did not have centralised air conditioning controlling indoor temperatures (10). An observational field study in a London office identified both the ability to control the local environment and noise levels as factors which can affect comfort, health and, consequently, productivity (26). An intervention study in an office in Singapore found that participants were more satisfied with temperatures in the closer-to-ambient $26-27^{\circ} \mathrm{C}$ range with self-regulated control of ceiling fans than they were at the more typical climate-controlled $23^{\circ} \mathrm{C}$ (with no ceiling fan), presenting the office with the opportunity to save significant amounts of energy (and money) by reducing comfort cooling (27).

Meta-analyses of published studies investigating the links between indoor environment and worker performance have also been conducted $(7,28)$. Seppänen's analysis found that within the $21-24^{\circ} \mathrm{C}$ temperature range, performance remained unaffected, but that worker performance decreased by $2 \%$ for every $1^{\circ} \mathrm{C}$ increase in temperature above $25^{\circ} \mathrm{C}$. Al Horr's review of the literature identified eight IEQ factors that influenced occupant productivity in office environments, namely indoor air quality and ventilation; thermal comfort; lighting and daylighting; noise and acoustics; office layout; biophilia and views; look and feel; location and amenities. These factors were found to significantly interact and crossover (e.g. levels of daylighting and thermal comfort had a direct interaction, and lower temperatures corresponded to improved perception of air quality). A meta-analysis of occupant surveys taken from fifty lowenergy non-domestic buildings in the UK found that $57 \%$ of workspaces reported an increase in perceived productivity due to the perceived environmental conditions (29). Perceived productivity increased when occupants were more satisfied with the indoor temperature, noise and lighting. Conversely perceived productivity decreased when the indoor air was perceived as stuffy and smelly.

The body of research which suggests a link between indoor environment and perceived productivity in workplaces continues to grow. However, finding empirical evidence from real-world working environments continues to be a challenge. Isolating the influencing factors amidst the statistical noise of other variables is inherently difficult but nevertheless is what that this paper seeks to address. 


\section{Overview of case study office environments}

The two case study buildings (Figure 1) involved in this research represented contrasting examples of typical office workspaces in the UK. Case study ' $\mathrm{K}$ ' was a naturally ventilated eight-storey building, constructed in 1938. It underwent a major refurbishment in 1995, which included the installation of fan coiled heating and cooling units (FCUs) and double glazed windows. Desks, carpets and other furnishings in the case-study workspaces were upgraded (replaced) in 2015. It was located in central London next to a busy roundabout. The case study working environment was on the seventh floor, which comprised of two open-plan administrative departments, approximately $600 \mathrm{~m}^{2}$ with 120 workstations. The average daily occupancy was 88, with the majority working at the same desk each day and only a small minority hotdesking. Occupants were able to control lighting locally and open and close the windows at will. The FCUs were controlled centrally. It was an owner-occupied building.

In contrast, case study ' $N$ ' was a mechanically ventilated three-storey building, constructed in 2004. It was located in a business park surrounded by woodlands in southern England. The case study working environments were located on the second and third floors and comprised of two open-plan administrative departments, approximately $2900 \mathrm{~m}^{2}$ with 260 workstations. The average daily occupancy was 155 , with the majority working at the same desk each day and only a small minority hotdesking. The windows in the workspaces were not openable, and lighting, heating, cooling and ventilation were controlled centrally. The facilities were managed by an on-site external FM company using BMS. Operating hours during the working days in both case study buildings were from 08:30 to 17:30.
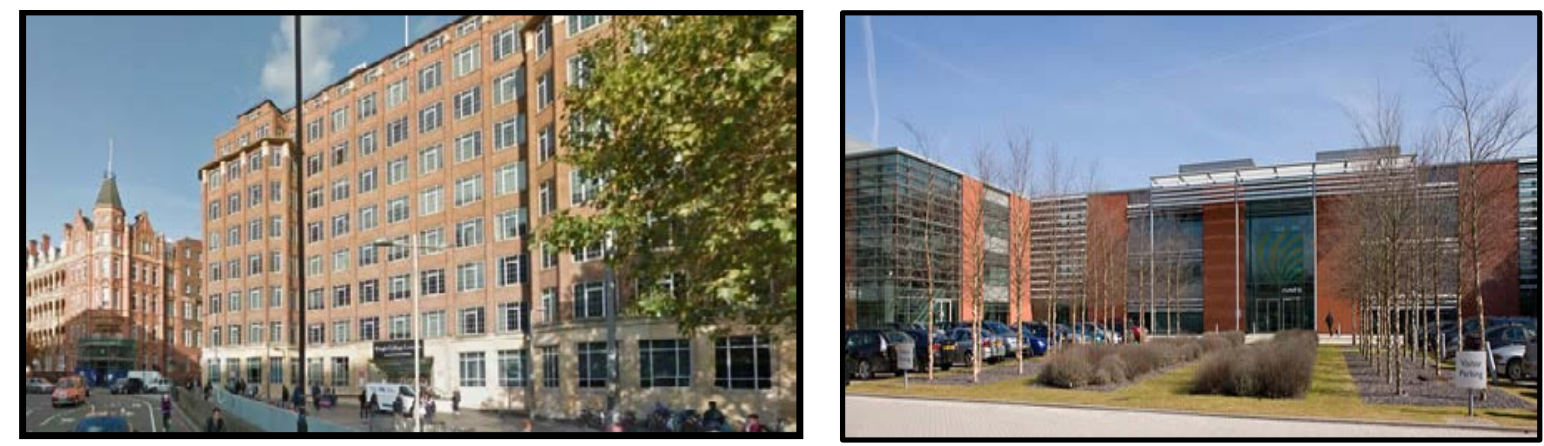

Figure 1 The two case study buildings: Case study ' $K$ ' (left) and case study ' $N$ ' (right)

\section{Methodology}

In order to understand the relationship between indoor environment and occupant productivity, the methodology adopted an essentially three-pronged approach which involved (a) physical monitoring of the indoor and outdoor environments, (b) transverse and longitudinal surveys to measure occupant perception of their indoor environment, comfort levels and perception of their own productivity, and (c) performance tasks, used as a proxy measure of their productivity. Additional business output metrics (the number of calls made or e-mails sent), and HR data (absentee rates) were also collected. However, these data sets proved to be either incomplete, 
or not of high enough resolution, to provide any meaningful statistics that could be related to the indoor environment with any confidence. This methodological approach is represented in Figure 2, which also shows the number of responses gained during the study.

\section{Case-studies}

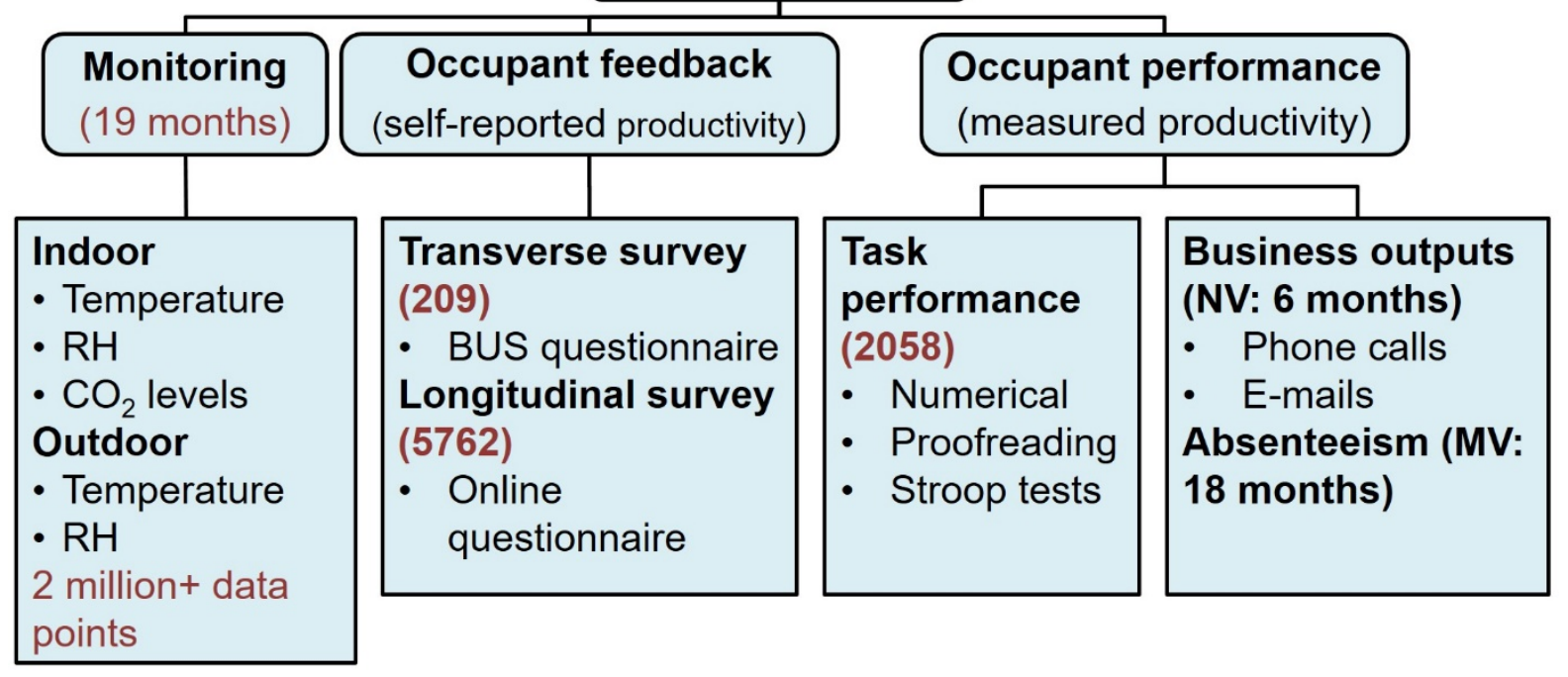

Figure 2 Methodology

The environmental monitoring began in spring 2017 and continued through to September 2018 - approximately 19 months in total. The monitoring devices (Table 1) recorded indoor temperature, $\mathrm{RH}$ and $\mathrm{CO}_{2}$ concentration and outdoor temperature and $\mathrm{RH}$, all at five-minute resolution. The devices were deployed throughout the case study offices, with the areas divided into zones (six zones in case study ' $\mathrm{K}$ ', twenty zones in case study ' $N$ '), each zone representing approximately 6-12 occupants. This allowed localized conditions to be monitored and cross-related to individual occupants and their time-stamped responses to the surveys and performance tasks.

Table 1 Specifications for the installed data loggers.

\begin{tabular}{|c|c|c|}
\hline Data logger & Measure & Specifications \\
\hline 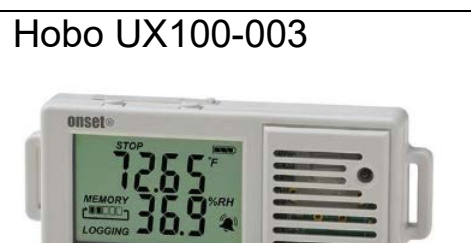 & Temperature & $\begin{array}{l}\text { Range: }-20^{\circ} \mathrm{C} \text { to }+70^{\circ} \mathrm{C} \\
\text { Accuracy: } \pm 0.21^{\circ} \mathrm{C} \text { (from } 0^{\circ} \mathrm{C} \text { to } \\
50^{\circ} \mathrm{C} \text { ) } \\
\text { Resolution: } 0.024^{\circ} \mathrm{C} \text { at } 25^{\circ} \mathrm{C}\end{array}$ \\
\hline Dimensions: $37 \times 85 \times 15 \mathrm{~mm}$ & $\mathrm{RH}$ & $\begin{array}{l}\text { Range: } 15 \% \text { to } 95 \% \\
\text { Accuracy: } \pm 3.5 \% \text { from } 25 \% \text { to } 85 \% \\
\text { Resolution: } 0.07 \% \text { at } 25 \%\end{array}$ \\
\hline HOBO U12-012 & Temperature & $\begin{array}{l}\text { Range: }-20^{\circ} \mathrm{C}-+70^{\circ} \mathrm{C} \\
\text { Accuracy: } \pm 0.35^{\circ} \mathrm{C} \text { from } 0^{\circ} \mathrm{C} \text { to } \\
50^{\circ} \mathrm{C}\end{array}$ \\
\hline
\end{tabular}




\begin{tabular}{|c|c|c|}
\hline & & Resolution: $0.03^{\circ} \mathrm{C}$ at $25^{\circ} \mathrm{C}$ \\
\hline $\begin{array}{l}\text { Dimensions: } \\
58 \times 74 \times 22 \mathrm{~mm}\end{array}$ & $\mathrm{RH}$ & $\begin{array}{l}\text { Range: } 5 \%-95 \% \\
\text { Accuracy: } \pm 2.5 \% \text { from } 10 \% \text { to } 90 \% \\
\text { Resolution: } 0.03 \%\end{array}$ \\
\hline $\begin{array}{l}\text { Tinytag } \mathrm{CO}_{2}-\mathrm{TGE}-0011 \\
\text { Dimensions: } \\
85 \times 100 \times 26 \mathrm{~mm}\end{array}$ & $\mathrm{CO}_{2}$ concentration & $\begin{array}{l}\text { Range: } 0-5000 \mathrm{ppm} \\
\text { Accuracy: }< \pm(50 \mathrm{ppm} \text { or } 3 \% \text { of } \\
\text { measured value }) \\
\text { Resolution: } 0.1 \mathrm{ppm}\end{array}$ \\
\hline 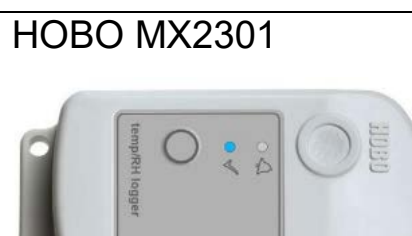 & $\begin{array}{l}\text { Outdoor } \\
\text { temperature }\end{array}$ & $\begin{array}{l}\text { Range: }-40^{\circ} \mathrm{C} \text { to }+70^{\circ} \mathrm{C} \\
\text { Accuracy: } \pm 0.25^{\circ} \mathrm{C} \text { from }-40^{\circ} \mathrm{C} \text { to } \\
0^{\circ} \mathrm{C}, \pm 0.2^{\circ} \mathrm{C} \text { from } 0^{\circ} \mathrm{C} \text { to } 70^{\circ} \mathrm{C} \\
\text { Resolution: } 0.04^{\circ} \mathrm{C}\end{array}$ \\
\hline $\begin{array}{l}\text { Dimensions: } \\
\text { 102x38mm }\end{array}$ & Outdoor RH & $\begin{array}{l}\text { Range: } 0 \% \text { to } 100 \% \\
\text { Accuracy: } \pm 2.5 \% \text { from } 10 \% \text { to } 90 \% \\
\text { Resolution: } 0.05 \%\end{array}$ \\
\hline $\begin{array}{l}\text { Tinytag TGP-4500 } \\
\text { (c) } \quad \text { a }\end{array}$ & $\begin{array}{l}\text { Outdoor } \\
\text { temperature }\end{array}$ & $\begin{array}{l}\text { Range: }-25^{\circ} \mathrm{C} \text { to }+85^{\circ} \mathrm{C} \\
\text { Accuracy: } \pm 0.5^{\circ} \mathrm{C} \text { from } 0^{\circ} \mathrm{C} \text { to } 40^{\circ} \mathrm{C} \\
\text { Resolution: } 0.01^{\circ} \mathrm{C}\end{array}$ \\
\hline $\begin{array}{l}\text { Dimensions: } \\
102 \times 38 \mathrm{~mm}\end{array}$ & Outdoor RH & $\begin{array}{l}\text { Range: } 0 \%-100 \% \\
\text { Accuracy: } \pm 3 \% \text { at } 25 \% \text { to } 90 \% \\
\text { Resolution: }<0.3 \%\end{array}$ \\
\hline
\end{tabular}

The transverse Building Use Studies (BUS) survey was conducted in both case study workspaces during spring, 2017 at the beginning of the project. It provided an overview of occupant perception of their working environment, with over 40 quantitative and qualitative questions covering aspects such as thermal comfort, ventilation, lighting, noise, personal control, and perception changes to health and productivity due to the building environment (30). Surveys were distributed to members of staff at the start of the working day and collected later on the same day. Case study ' $K$ ' provided 99 survey responses (representing a response rate of approximately $80 \%$ ), and case study ' $N$ ' provided 109 survey responses (representing a response rate of approximately $40 \%$ ).

The design of the online longitudinal survey was informed by the results of the transverse survey. These surveys were conducted online. An e-mail link to the surveys 
was sent three times a day (morning, early afternoon and late afternoon), with responses time-stamped and with desk numbers, enabling them to be matched with the nearest environmental loggers. The surveys were conducted during a baseline period of three weeks during the spring/summer of 2017, and during four-week 'intervention' periods between autumn 2017 and summer 2018. During these intervention periods, the surveys were conducted on Mondays and Tuesdays, and performance tasks conducted on Wednesdays, Thursdays and Fridays. Case study ' $\mathrm{K}$ ' had two intervention periods, the first during March/April 2018 and the second during July 2018. Case study ' $N$ ' also had two intervention periods, the first during October/November 2017 and the second during May/June 2018. Case study ' $\mathrm{K}$ ' provided a total of 3082 survey responses (representing a response rate of approximately $20 \%$ overall), whereas case study ' $N$ ' provided a total of 2680 survey responses (representing a response rate of approximately $10 \%$ overall).

The simulated performance tasks were designed to test respondents' cognitive capability and were used as a proxy measure for productivity. Both the test score and the time taken to complete the task were recorded. The tasks were designed to represent the typical tasks undertaken in the case study workspaces: Numerical tests asked respondents to (mentally) solve simple arithmetical questions; proofreading tasks asked respondents to identify spelling errors in short paragraphs of text (generally between 80 and 120 words in length); and Stroop tests, an established interference test asking respondents to differentiate between the colour of text and the word. These performance tasks were delivered in conjunction with the longitudinal surveys, as outlined above. Case study ' $\mathrm{K}$ ' provided a total of 1179 task responses (representing a response rate of approximately $16 \%$ overall), whereas case study ' $N$ ' provided a total of 1186 surveys (representing a response rate of approximately $8 \%$ overall).

\section{Results: Indoor environment}

\subsection{Temperature}

Indoor temperatures were monitored throughout both case study workspaces over nineteen months. Outdoor temperatures at both sites were also monitored for the majority of this period. Compared to case study ' $\mathrm{N}$ ', case study ' $\mathrm{K}$ ' was found to experience a significantly greater range of temperatures over the whole monitoring period (Figure 3), monthly (Figure 4) and even over the course of a typical working day (Figure 5).

In case study ' $\mathrm{K}$ ' during the heating season (defined here as from October to April), the mean indoor temperature during working hours was $23.8^{\circ} \mathrm{C}, 0.3^{\circ} \mathrm{C}$ lower than the median indoor temperature of $24.1^{\circ} \mathrm{C}$, skewed by temperatures being as low as $15.6^{\circ} \mathrm{C}$ at the start of the working day in the depths of winter. Occupants commented on how they would often come to work in the winter wearing layers of clothes due to the broad range of temperatures they were expecting to experience over the day (up to $8^{\circ} \mathrm{C}$ range during working hours). During the heating season, the recommended indoor temperature range of $21-23^{\circ} \mathrm{C}$ was exceeded for $58 \%$ of working hours, exceeding $25^{\circ} \mathrm{C}$ for $11 \%$ of working hours reaching as high as $28.1^{\circ} \mathrm{C}$ on occasion. Indoor temperatures were below $21^{\circ} \mathrm{C}$ for $18 \%$ of working hours, falling below $19^{\circ} \mathrm{C}$ for $8 \%$ of working hours. 
Case study ' $N$ ', by contrast, experienced much more stable temperatures during the heating season. Mean and median indoor temperatures were approximately the same: 23.6 and $23.7^{\circ} \mathrm{C}$ respectively. Indoor temperatures rarely fell below the recommended $21^{\circ} \mathrm{C}$, and although they exceeded $23^{\circ} \mathrm{C}$ for $58 \%$ of working hours, they only exceeded $25^{\circ} \mathrm{C}$ for $1 \%$ of working hours, with a peak of $25.7^{\circ} \mathrm{C}$.

The difference in indoor temperature profiles for the heating and non-heating seasons was much more evident in case study ' $\mathrm{K}$ ' than in case study ' $\mathrm{N}$ '. Case study ' $\mathrm{K}$ 's mean and median indoor temperature was 24.8 and $24.7^{\circ} \mathrm{C}$ respectively (an increase of $1.0^{\circ} \mathrm{C}$ for the mean and $0.6^{\circ} \mathrm{C}$ for the median). During the non-heating season, the recommended indoor temperature range is $22-24^{\circ} \mathrm{C}$. In case study ' $\mathrm{K}$ ', this was exceeded for $61 \%$ of working hours, with temperatures in excess of $26^{\circ} \mathrm{C}$ for $15 \%$ of working hours, reaching in excess of $30^{\circ} \mathrm{C}$ on occasion. Although not as low as during the heating season, indoor temperatures were still below the recommended $22^{\circ} \mathrm{C}$ for $8 \%$ of working hours.

In case study ' $\mathrm{N}$ ', the mean and median indoor temperatures during the non-heating season were also approximately the same: $24.0^{\circ} \mathrm{C}$, only $0.3-0.4^{\circ} \mathrm{C}$ higher than in the heating season. Although indoor temperatures exceeded $24^{\circ} \mathrm{C}$ for $38 \%$ of working hours, they only exceeded $26^{\circ} \mathrm{C}$ for $2 \%$ of working hours, with a peak of $26.6^{\circ} \mathrm{C}$.

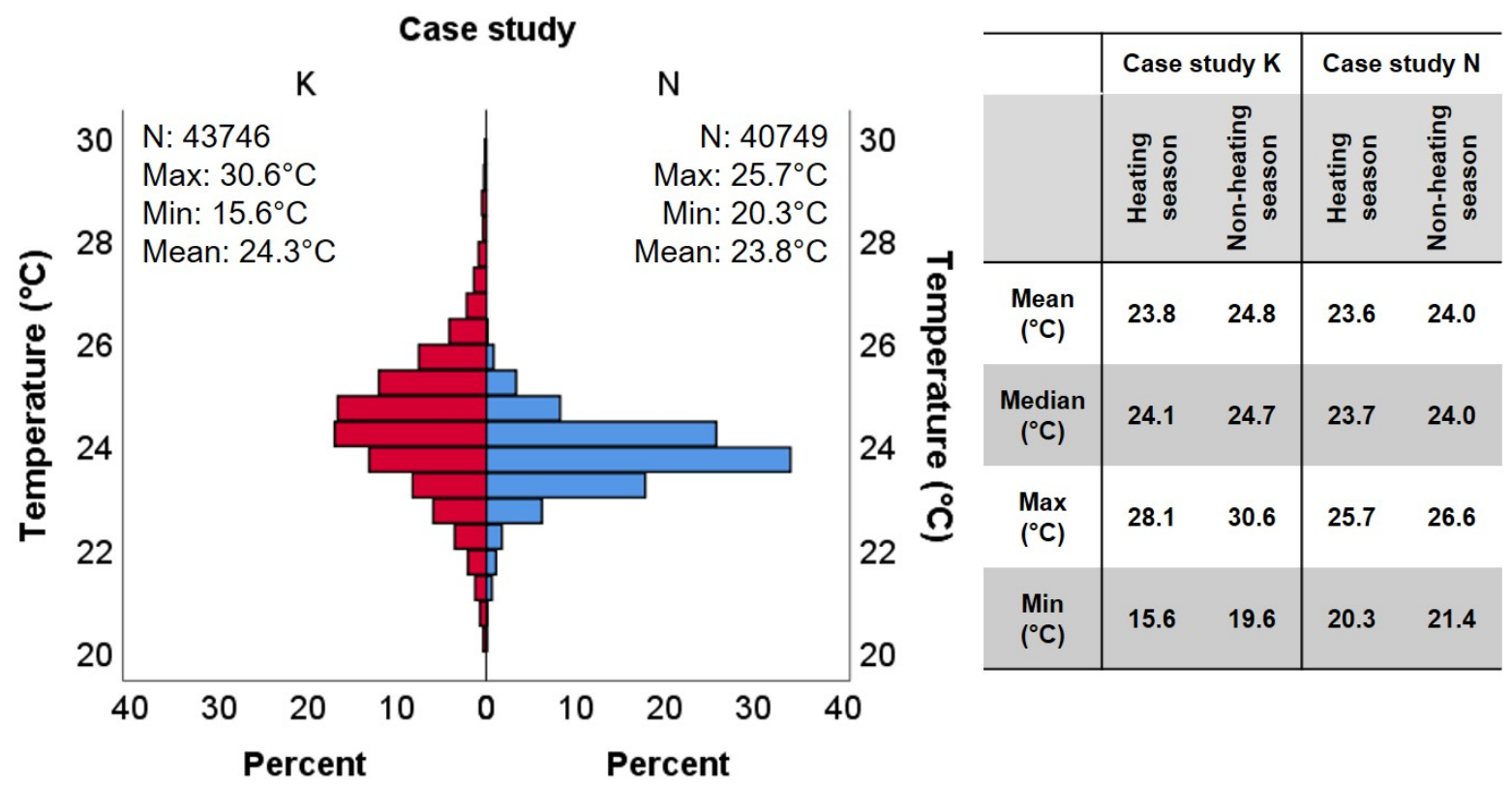

Figure 3 Hourly average working hours indoor temperatures (Mar 2017 - Sep 2018) (left) and descriptive statistics for the heating and non-heating seasons in both case study buildings (right)

The distribution of indoor temperatures during working hours is plotted on a month-bymonth basis for the two case study buildings in Figure 4. This further illustrates both the much wider range of indoor temperatures experienced each month in case study ' $\mathrm{K}$ ' compared to case study ' $\mathrm{N}$ ', and the much greater seasonal variation in temperatures experienced in case study ' $K$ ' compared to case study ' $N$ '. 


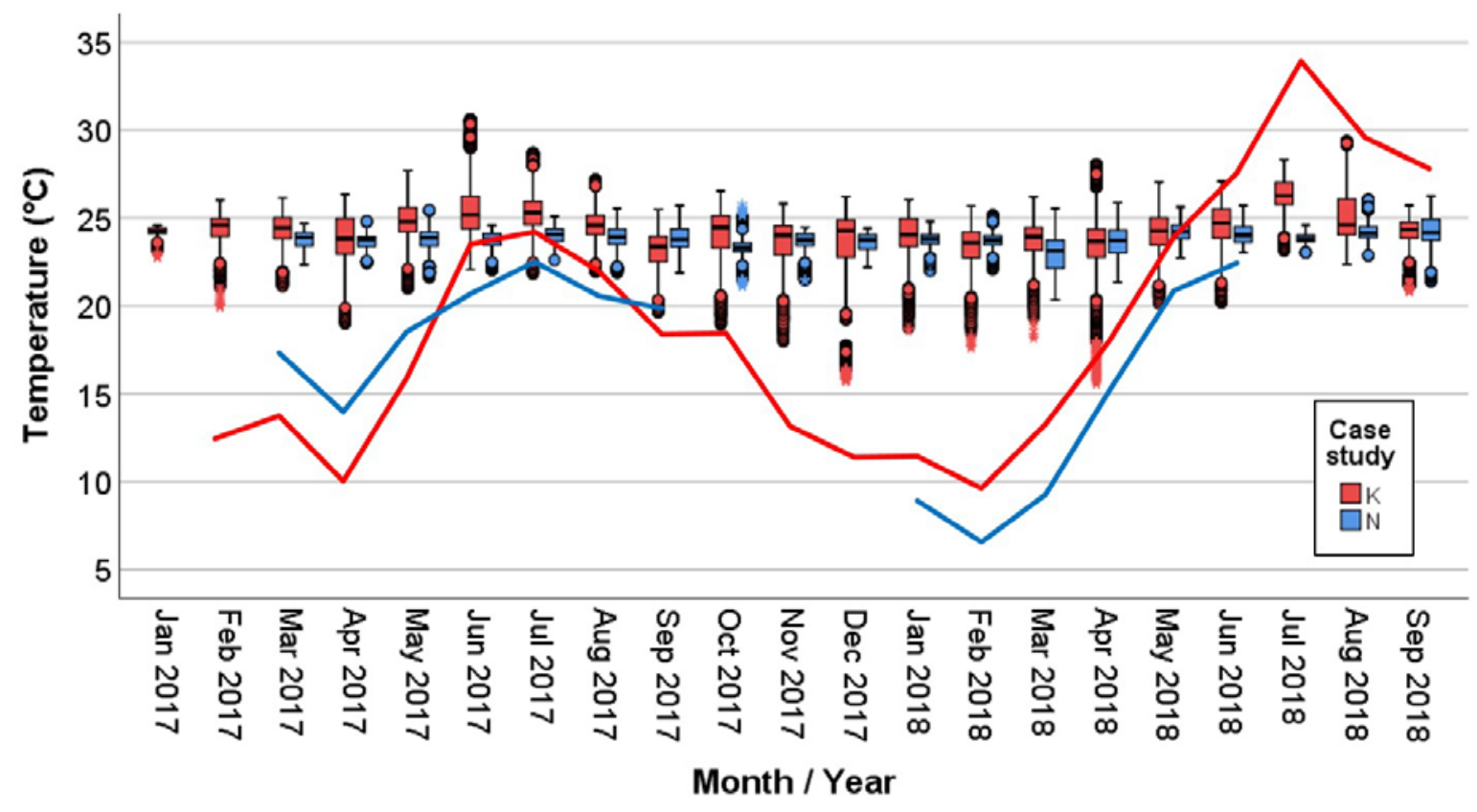

Figure 4 Boxplot showing monthly distribution of indoor temperatures during working hours in the two case-study workspaces, with line plots showing monthly average outdoor temperatures at the two sites.

Taking a sample heating season month (February 2018) and non-heating season month (July 2017), the average diurnal temperature profiles have been plotted (Figure 5). Indoor temperatures vary by an average of around $3.0^{\circ} \mathrm{C}$ in the heating season and $2.5^{\circ} \mathrm{C}$ in the non-heating season in case study ' $\mathrm{K}$ ', whereas in case study ' $\mathrm{N}$ ', the average diurnal temperature range is much smaller: around $1.5^{\circ} \mathrm{C}$ in both the heating and non-heating seasons.
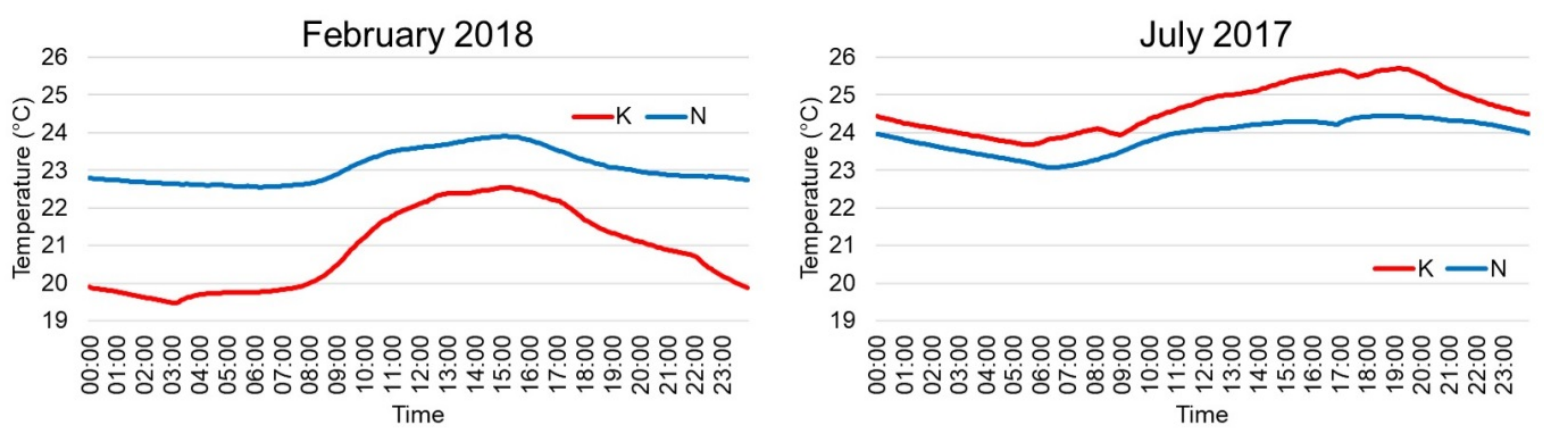

Figure 5 Diurnal indoor temperature profiles for sample heating season month (February 2018) and nonheating season month (July 2017) in both case studies.

\section{2 $\mathrm{CO}_{2}$ concentration}

As with indoor temperatures, $\mathrm{CO}_{2}$ concentrations varied much more in the naturally ventilated case study ' $K$ ' than in the mechanically ventilated case study ' $N$ ' (Figure 6).

In case study ' $\mathrm{K}$ ' during the heating season, $\mathrm{CO}_{2}$ concentrations reached almost 2700 ppm during working hours, when the cold outdoor temperatures made it very unlikely that occupants would open the windows to allow venting of $\mathrm{CO}_{2}$. During the heating season, both mean and median $\mathrm{CO}_{2}$ concentrations exceeded $1000 \mathrm{ppm}$, and were 
over $1000 \mathrm{ppm}$ for $63 \%$ of working hours. In contrast, case study ' $\mathrm{N}$ ' occupants only experienced $\mathrm{CO}_{2}$ concentrations over $1000 \mathrm{ppm}$ for $9 \%$ of working hours during the heating season, with mean and median concentrations well below 800 ppm.

However, the statistics were significantly different during the non-heating season when the high temperatures in case study ' $\mathrm{K}$ ' meant that occupants had the many of the windows open for many of the occupied hours. Consequently the mean and median $\mathrm{CO}_{2}$ concentrations plummeted to $795 \mathrm{ppm}$ and $726 \mathrm{ppm}$ respectively, in the same region as the mean and median concentrations in case study ' $N$ ' (Figure 6). Although case study ' $\mathrm{K}$ ' still experienced periods of high $\mathrm{CO}_{2}$ concentration, up to $2434 \mathrm{ppm}$, these were less common than during the heating season, and concentrations only exceeded $1000 \mathrm{ppm}$ for $18 \%$ of working hours. $\mathrm{CO}_{2}$ concentrations in case study ' $\mathrm{N}$ ' during the non-heating season decreased slightly, with mean and median concentrations around $50 \mathrm{ppm}$ lower than during the heating season, and a peak concentration less than $300 \mathrm{ppm}$ lower than during the heating season. Being a mechanically ventilated building, the lack of significant seasonal variation was to be expected, the slightly lower levels possibly the result of slightly lower occupancy levels during the summer months when more occupants may have been on leave.

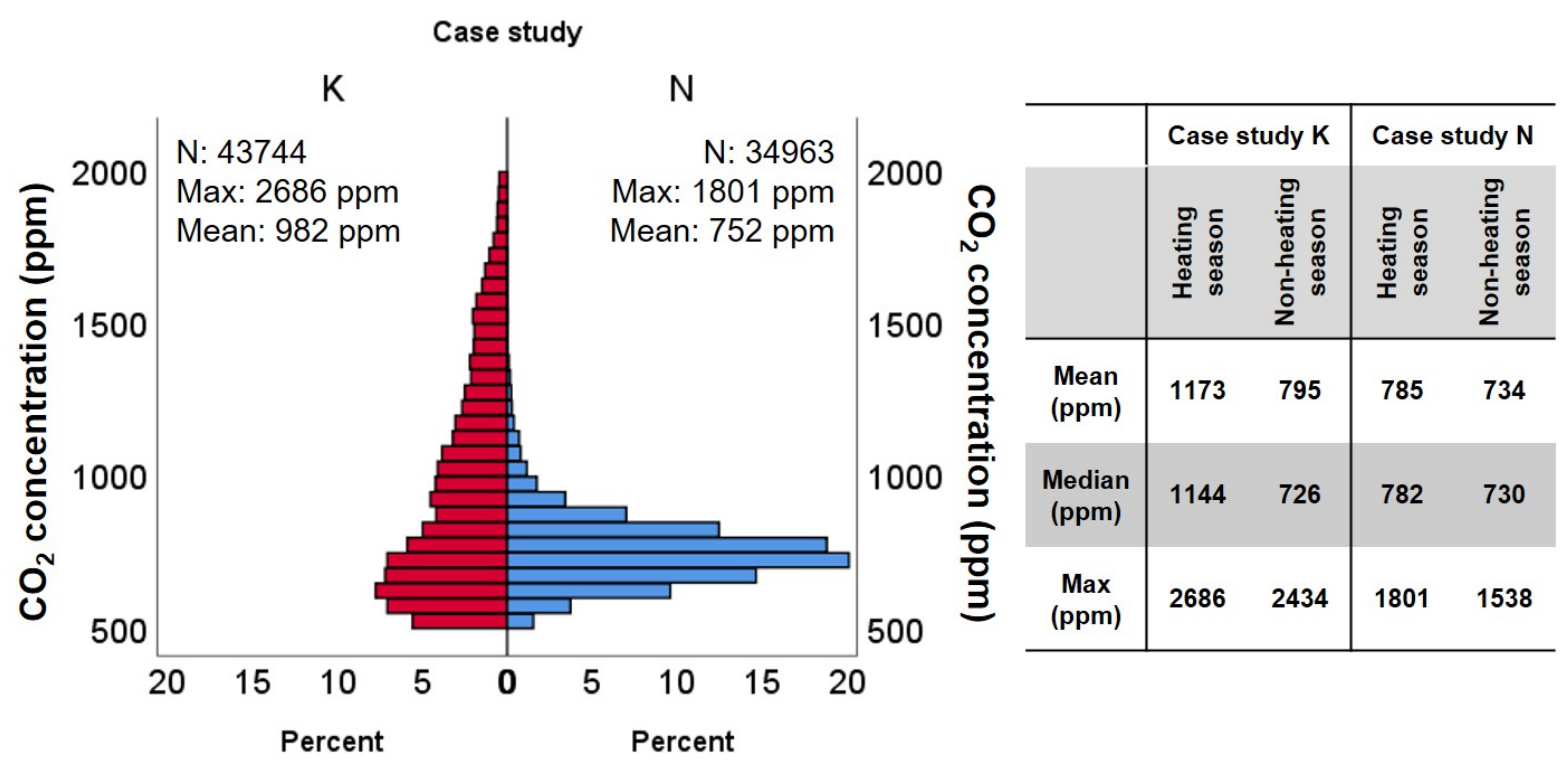

Figure 6 Working hours indoor $\mathrm{CO}_{2}$ concentration (Mar 2017 - Sep 2018) (left) and descriptive statistics for the heating and non-heating seasons in both case study buildings (right).

The monthly distribution of $\mathrm{CO}_{2}$ concentrations during working hours for the two case study buildings is plotted in Figure 7 . This further illustrates both the much wider range of $\mathrm{CO}_{2}$ concentrations experienced each month in case study ' $\mathrm{K}$ ' compared to case 
study ' $\mathrm{N}$ ', and the much greater seasonal variation in $\mathrm{CO}_{2}$ concentrations experienced in case study ' $\mathrm{K}$ ' compared to case study ' $\mathrm{N}$ '.

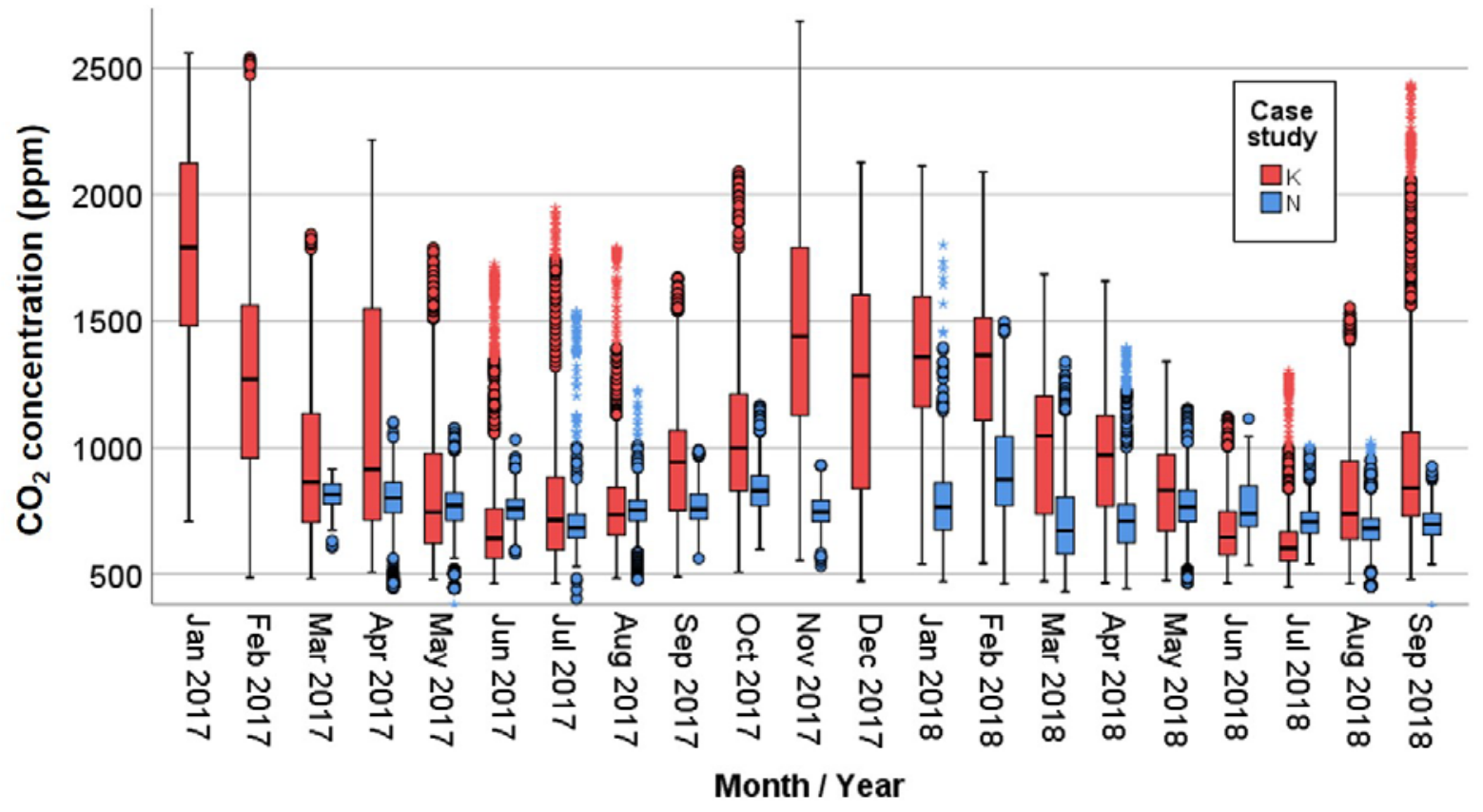

Figure 7 Boxplot showing monthly distribution of indoor $\mathrm{CO}_{2}$ concentrations during working hours in the two case-study workspaces.

Taking the same sample heating and non-heating season months (February 2018 and July 2017 respectively) as for indoor temperature, the average diurnal $\mathrm{CO}_{2}$ concentration profiles have been plotted (Figure 8). In both case studies and in both heating and non-heating seasons, the shape of the profiles was similar: at the start of the working day, $\mathrm{CO}_{2}$ concentrations rise sharply as the workspace is occupied, by late morning the concentrations begin to plateau off and then from the end of the working day they decrease back to ambient levels. During the sample heating season month, the contrast between the two case studies is more evident. In case study ' $\mathrm{K}$ ', concentrations rose by around $700 \mathrm{ppm}$ within the space of less than three hours. Concentrations in case study ' $N$ ' rose more sharply, but within a couple of hours they had peaked, increasing by only around $400 \mathrm{ppm}$. The higher daytime concentrations meant that it took longer for levels to return to ambient in the evenings in case study ' $\mathrm{K}$ ' compared to case study ' $\mathrm{N}$ '. During the sample non-heating season month, the diurnal profiles are very similar, with both buildings only experiencing a rise in $\mathrm{CO}_{2}$ concentration of around 200 ppm during working hours. 

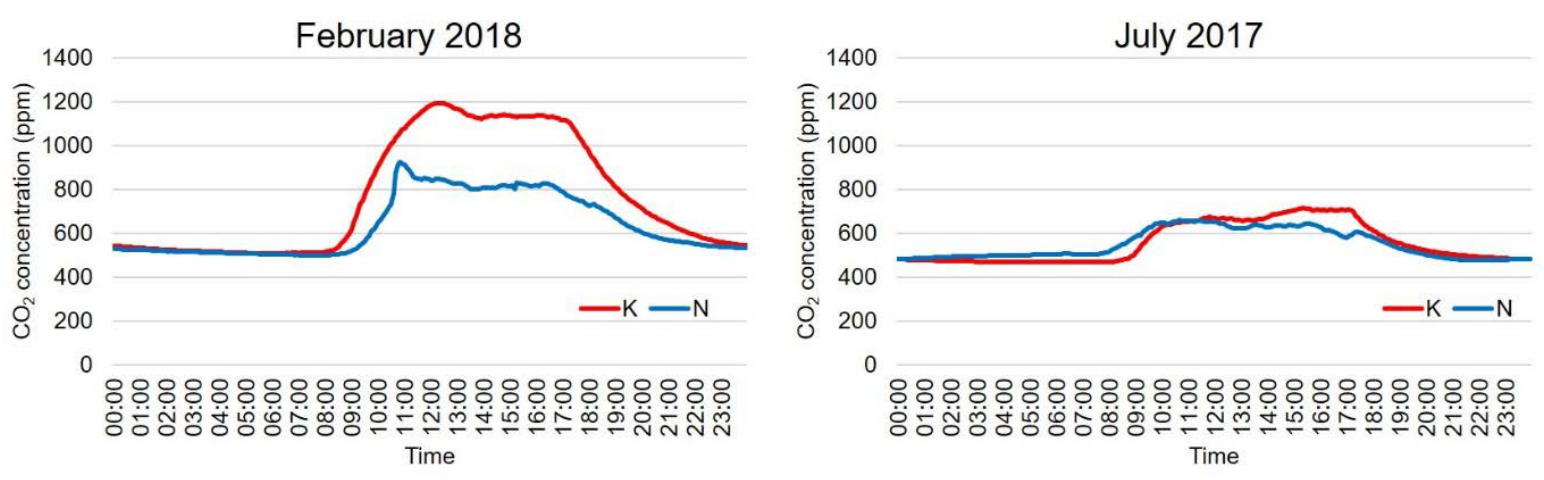

Figure 8 Average $\mathrm{CO}_{2}$ concentration in case studies $\mathrm{K}$ and $\mathrm{N}$ (indoor and outdoor) during sample months (Feb 2018, left, and Jul 2017, right)

\subsection{Relative humidity}

The levels of indoor relative humidity $(\mathrm{RH})$ in the two case studies were similar (Figure 9), with maximums in the $60-70 \%$ range and means in the $35-40 \%$ range during the heating season and $45-50 \%$ range in the non-heating season. The month-by-month boxplot distributions also followed a similar pattern in both case study buildings, the main significant difference being the inter-quartile range being greater in case study ' $\mathrm{K}$ ' during the non-heating season and greater in case study ' $\mathrm{N}$ ' during the heating season (Figure 10). In both case study buildings, indoor RH levels were higher during the non-heating season (Figure 11), in contrast to the outdoor trend. This was in part due to the effect of winter heating drying the air. It is also notable that the average $\mathrm{RH}$ levels were slightly higher in case study ' $\mathrm{K}$ ' than in case study ' $\mathrm{N}$ ' during the heating season, but slightly lower in case study ' $K$ ' than in case study ' $N$ ' during the nonheating season.

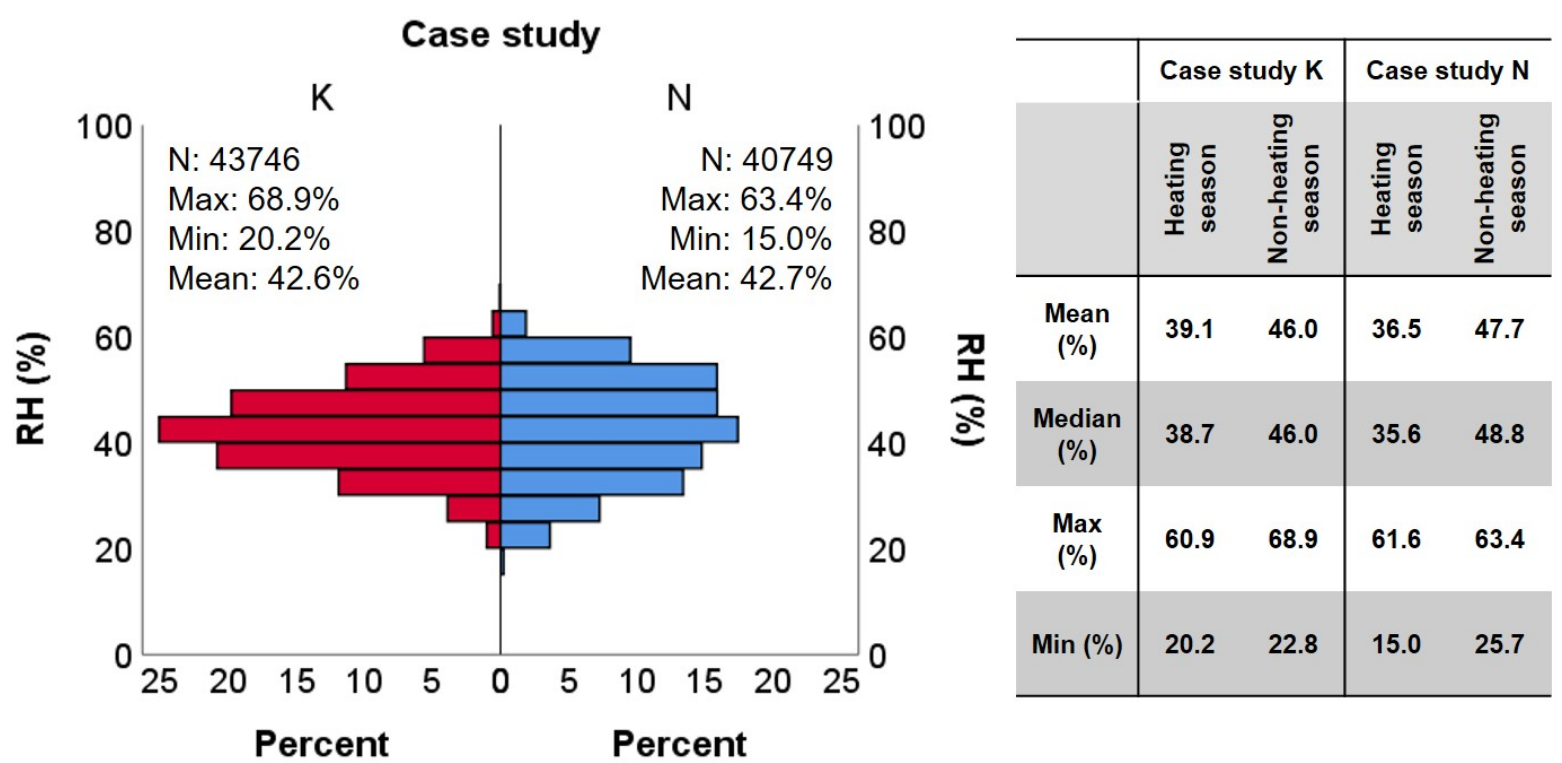

Figure 9 Working hours indoor RH (Mar 2017 - Sep 2018) (left) and descriptive statistics for the heating and non-heating seasons in both case study buildings (right). 


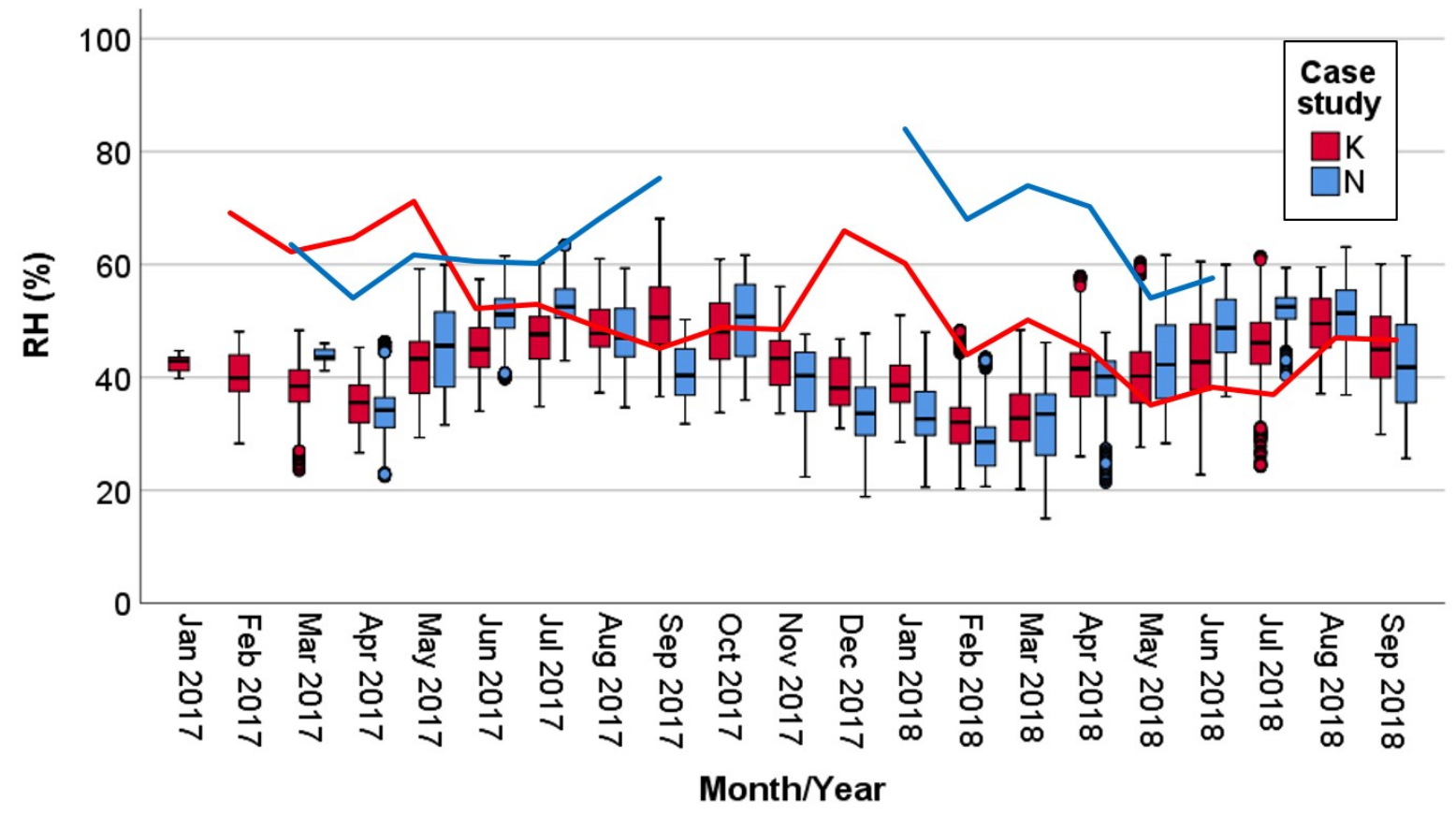

Figure 10 Boxplot showing monthly distribution of indoor RH during working hours in the two case-study workspaces, with line plots showing monthly average outdoor RH at the two sites.
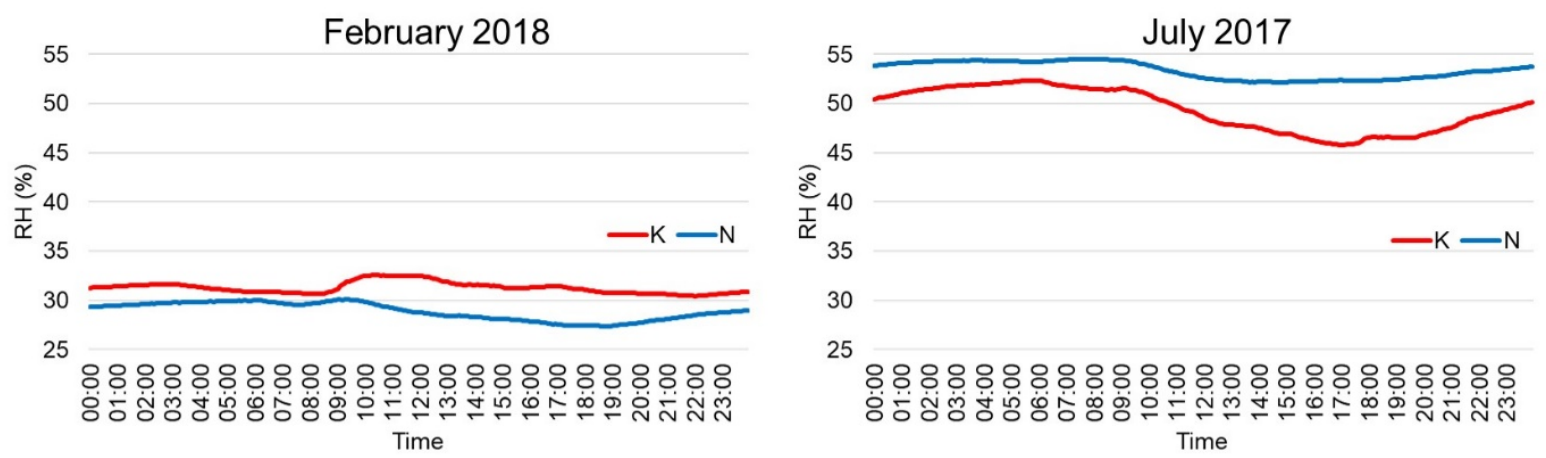

Figure 11 Average RH in case studies $\mathrm{K}$ and $\mathbf{N}$ (indoor and outdoor) during sample months (Feb 2018, left, and Jul 2017, right).

\section{Perceived productivity and indoor environment}

\subsection{Transverse survey of perceived productivity}

Transverse survey in the form of BUS survey was conducted in spring 2017 in each case study workspace. Respondents were asked to rate their overall comfort ("All things considered, how do you rate the overall comfort of the building environment?") on a scale from 1 (unsatisfactory) to 7 (satisfactory) (Figure 12, left). Both case study buildings had a skew towards the 'satisfactory' end of the scale. Although case study ' $N$ ' had a higher proportion of responses at ' 6 ' and ' 7 ', both case studies had $64 \%$ of responses in the more satisfactory 5-7 range. Although neither case study had any responses at the extreme ' 1 ' end of the scale, case study ' $N$ ' had $20 \%$ of responses in the less satisfactory 2-3 range, compared to only $14 \%$ of case study 'K' responses. 
Respondents were also asked how they perceived the building to affect their health ("Do you feel less or more healthy when you are in the building?") on a scale from 1 (less healthy) to 7 (more healthy) (Figure 12, right). In contrast to their comfort, in both buildings there was a strong skew towards the negative 'less healthy' end of the scale, with $40 \%$ of case study ' $K$ ' responses and $52 \%$ of case study ' $N$ ' responses in the 1-3 range. Only $10 \%$ of responses in each case study building were in the 'more healthy' 5-7 range. Of these, the case study ' $N$ ' responses were significantly more positive than the case study ' $K$ ' responses.
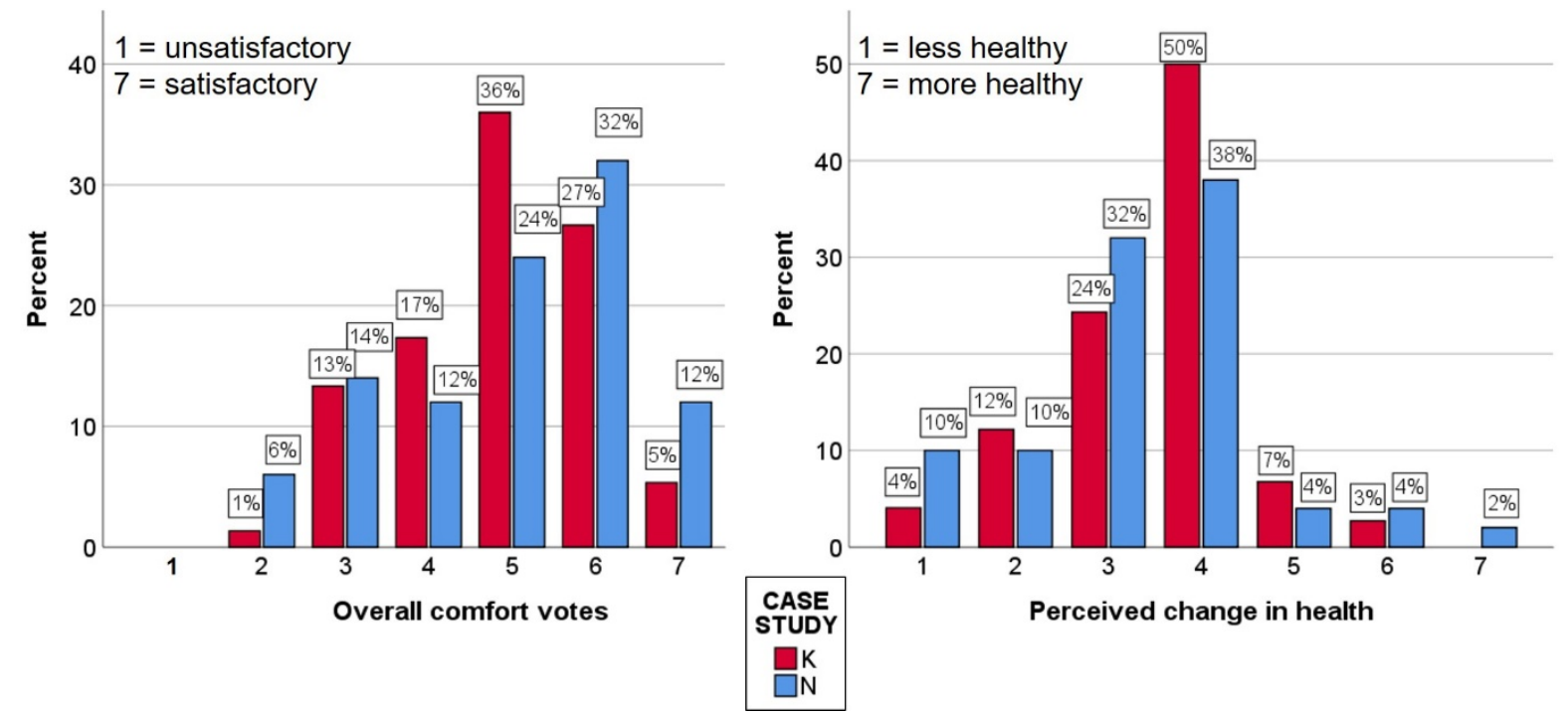

Figure 12 Distribution of overall comfort votes (left) and perceived change in health (right) for both case study buildings.

Respondents were also asked to judge how their productivity was affected by the building environment ("Please estimate how you think your productivity at work is decreased or increased by the environmental conditions in the building?"), with responses from "- $40 \%$ or less" to " $+40 \%$ or more" in $10 \%$ increments (Figure 13). Only $18 \%$ of responses in case study ' $\mathrm{K}$ ' and $20 \%$ of responses in case study ' $N$ ' were on the positive end of the scale, perceiving their productivity to be increased by their respective building's environment. Over half of the responses in each case study $(55 \%$ in ' $\mathrm{K}$ ' and $57 \%$ in ' $\mathrm{N}$ ') were on the negative end of the scale, perceiving their productivity to be decreased by their respective building's environment. 


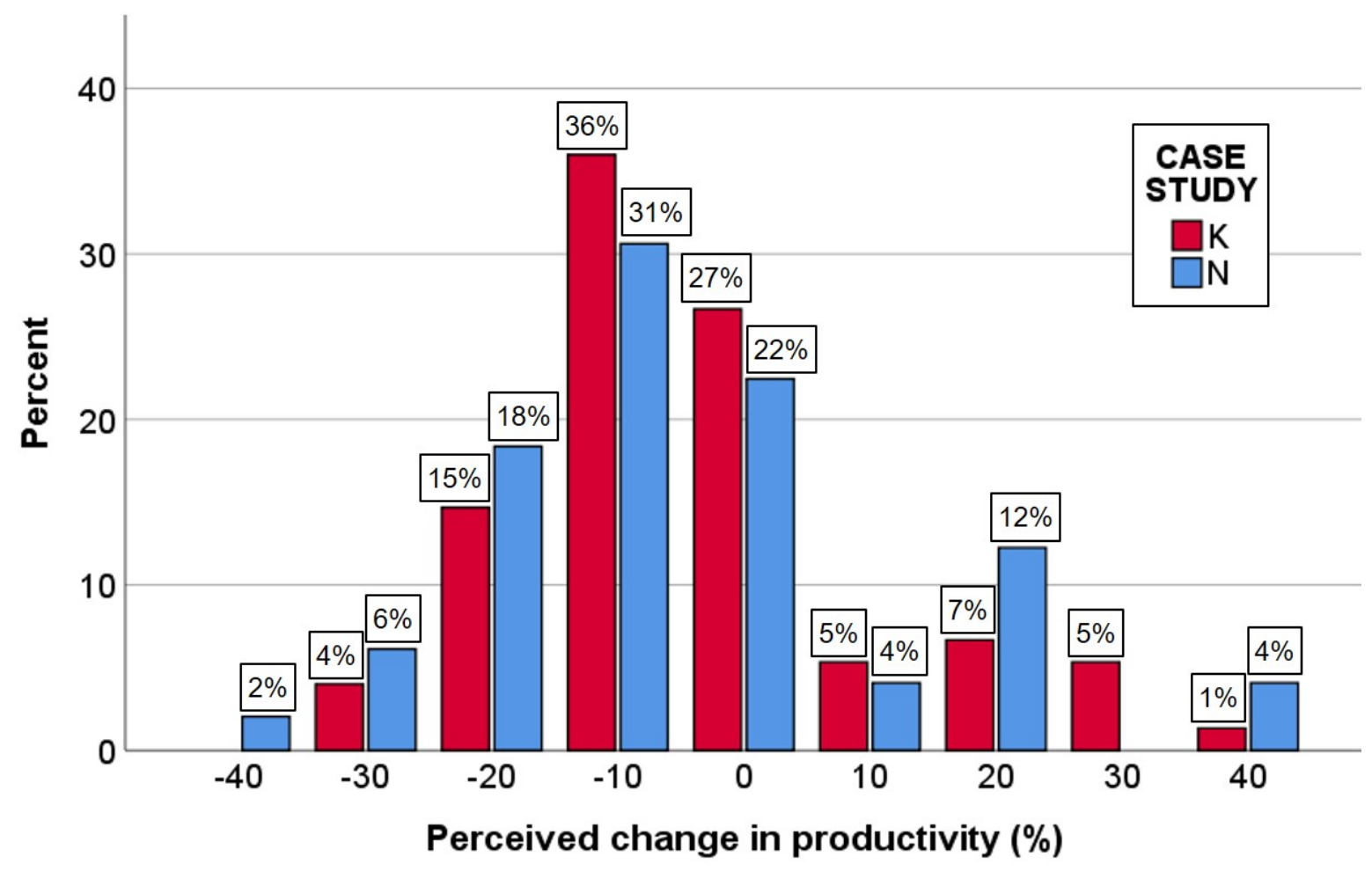

Figure 13 Distribution of responses to perceived change in productivity for both case study buildings.

It is worth noting that for all three of these questions (comfort, health and perceived productivity), the extreme ends of the scales, both positive and negative, had a larger proportion of responses from case study ' $N$ ' than case study ' $K$ '. Given the environmental conditions presented above, these distributions are interesting. It seems reasonable that overall comfort, perceived change in health and perceived change in productivity would receive more positive responses in case study ' $N$ ' than case study ' $K$ '. However, for case study ' $N$ ' to receive more negative responses than case study ' $K$ ' is perhaps surprising.

By treating the discrete responses to the survey questions as continuous variables, it was possible to find correlations between them. The responses which had the strongest correlations with perceived change in productivity were overall comfort and perceived change in health (Figure 14). The linear trend lines shown indicate that the less satisfied respondents were with their overall comfort, the more they felt that the building's environment was negatively affecting their productivity (Figure 14, left). It is notable that only at the 'satisfactory' 6-7 end of the scale do the trend lines cross into the positive perceived change in productivity.

The trend lines showing the relationship between perceived change in health and perceived change in productivity (Figure 14, right) indicate that the more respondents felt their health was improved by the building, the more they also felt their productivity was increased. The trend lines cross into the positive perceived change in productivity when perceived change in health is around the neutral 4 on the scale. The Spearman correlations ('R') shown were all significant at the 0.01 level. 

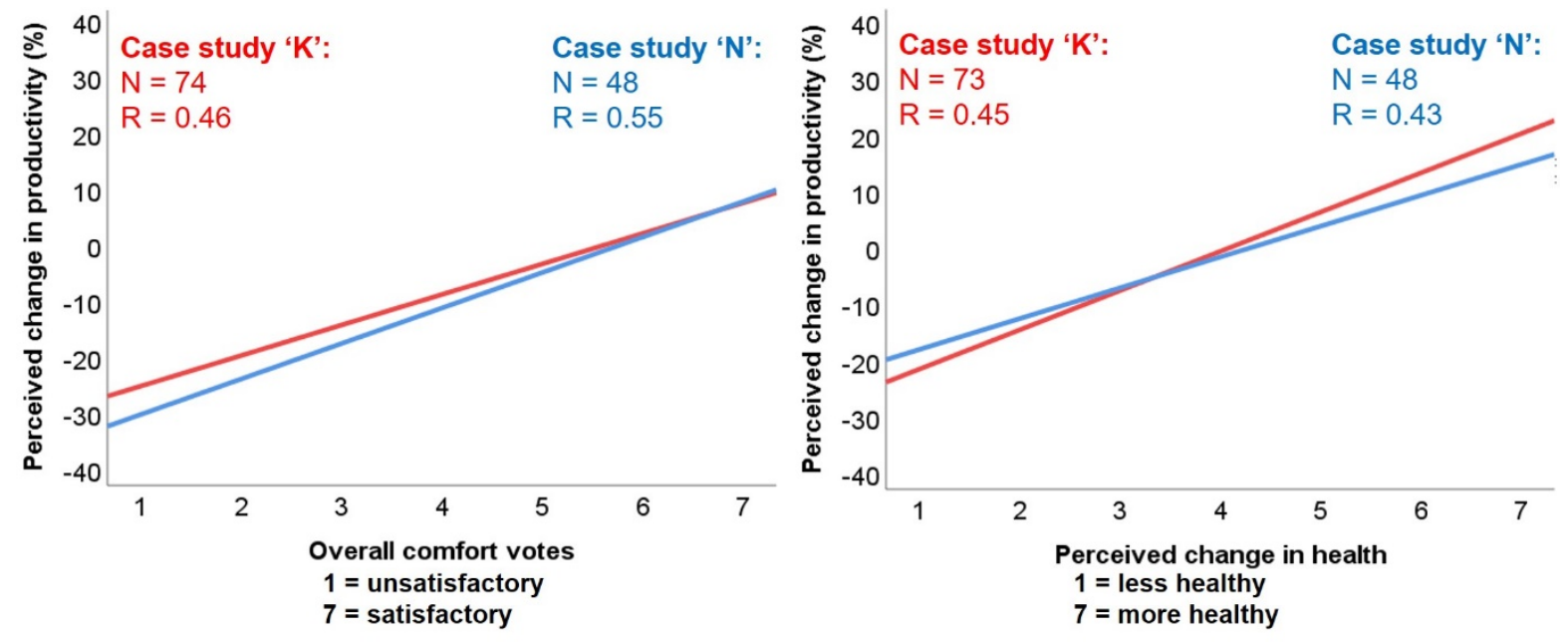

Figure 14 Relationship of overall comfort votes (left) and perceived change in health (right) with perceived change in productivity for both case study buildings.

Correlations were also found between some of the responses relating to the indoor temperature and air in the winter and summer (Table 2). Responses for temperature in winter and summer overall were on a scale from 1 ('uncomfortable') to 7 ('comfortable'), and for air in winter and summer overall were on a scale from 1 ('unsatisfactory') to 7 ('satisfactory'). When occupants found the temperatures uncomfortable or the air to be unsatisfactory, they perceived their productivity to be negatively affected. The non-parametric Spearman correlations shown in Table 2 indicate the strength of these relationships. Again, it is interesting that with more stable environmental conditions found in case study ' $N$ ', the correlations between the four comfort-related responses and perceived change in productivity were consistently stronger than the correlations in case study ' $\mathrm{K}$ '.

Table 2 Spearman's correlations between selected comfort responses and perceived change in productivity.

\begin{tabular}{|l|l|l|}
\hline & Case study K (n=74) & Case study N (n=48) \\
\hline $\begin{array}{l}\text { Temperature in winter: } \\
\text { overall }\end{array}$ & $\mathrm{R}=0.21$ & $\mathrm{R}=0.33^{*}$ \\
\hline Air in winter: overall & $\mathrm{R}=0.27^{*}$ & $\mathrm{R}=0.34^{*}$ \\
\hline $\begin{array}{l}\text { Temperature in } \\
\text { summer: overall }\end{array}$ & $\mathrm{R}=0.20$ & $\mathrm{R}=0.34^{*}$ \\
\hline Air in summer: overall & $\mathrm{R}=0.26$ & $\mathrm{R}=0.52^{* *}$ \\
\hline
\end{tabular}

${ }^{*}$ Correlation is significant at the 0.05 level (2-tailed)

${ }^{* *}$ Correlation is significant at the 0.01 level ( 2 tailed)

\subsection{Longitudinal online survey}

The BUS surveys provided an overview of occupants' perceptions of their working environments. The online surveys provided a series of snapshots which together provided a longitudinal insight into how occupants perceived their working 
environments. By indicating their desk number and time, it was possible to cross-relate their survey responses to the concurrent temperature, $\mathrm{RH}$ and $\mathrm{CO}_{2}$ concentration.

Occupants were asked to rate their current thermal comfort on a seven-point scale from 'much too cold' to 'much too warm' (Figure 15). The distribution of responses shows that occupants of case study ' $K$ ' were more likely to be on the cool end of the scale than the warm end (36\% of responses compared to $31 \%$ of responses respectively), whereas occupants of case study ' $N$ ' were more likely to be on the warm end of the scale than the cool end ( $40 \%$ of responses compared to $25 \%$ of responses respectively). Interestingly, in both case studies, $34 \%$ of responses were neutrally comfortable.

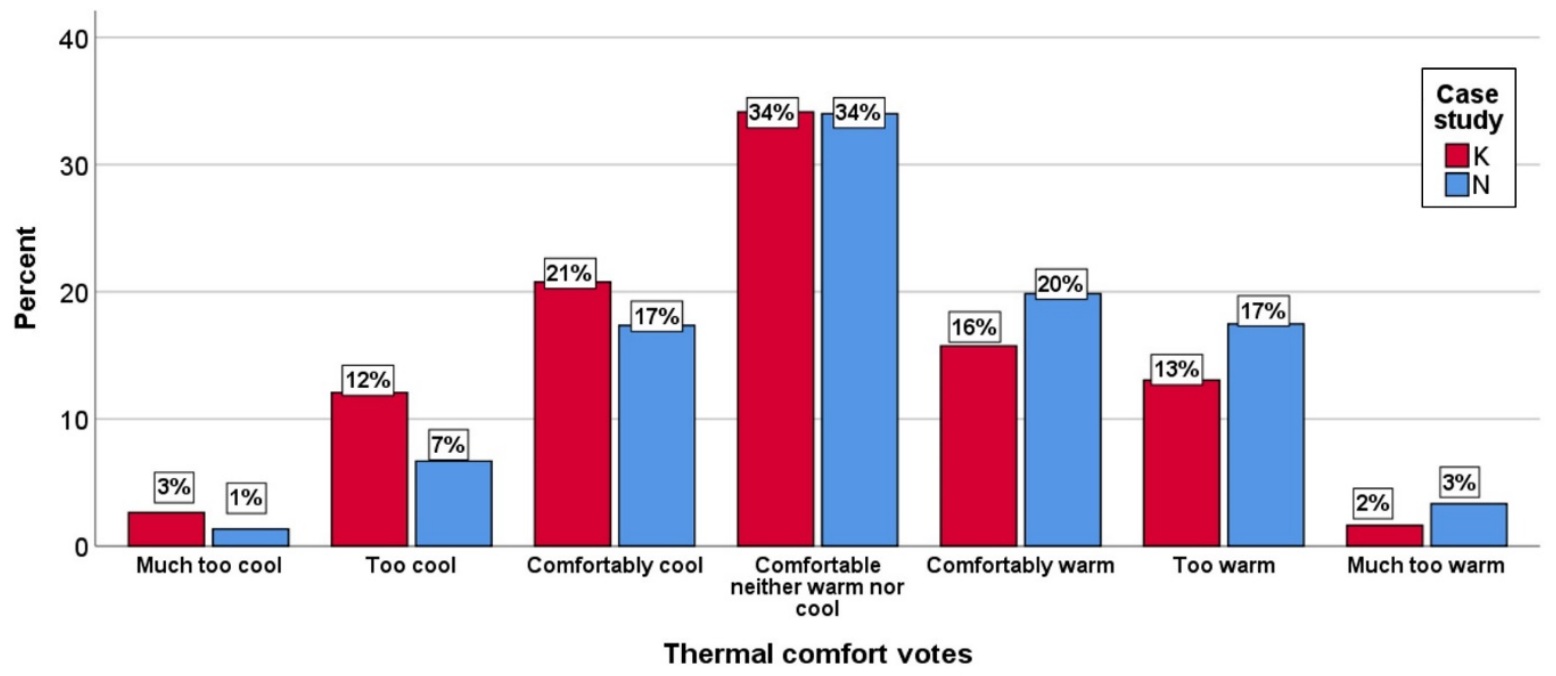

Figure 15 Distribution of thermal comfort votes in both case study workspaces.

Occupants were asked if they would prefer to be warmer or cooler, with responses on a five-point scale from 'much warmer' to 'much cooler' (Figure 16, left). In case study 'K', $23 \%$ of responses were on the 'warmer' end of the scale compared to $26 \%$ of responses on the 'cooler' end - an interesting contrast to the thermal comfort votes. In case study ' $\mathrm{N}$ ', only $14 \%$ of responses were on the warmer end of the scale compared to $37 \%$ on the cooler end, more in line with the thermal comfort votes. A slightly higher proportion of responses from case study ' $\mathrm{K}$ ' compared to case study ' $N$ ' were content with their thermal conditions and wanted no change (51\% compared to $48 \%$ ), which, having seen the temperature profiles of both buildings, was not what may have been expected. Comparing the thermal preference votes from surveys conducted in the heating and non-heating seasons, in case study ' $K$ ', $36 \%$ of responses were on the 'warmer' end of the scale during the heating season compared to only $12 \%$ during the non-heating season, whereas in case study ' $N$ ', $31 \%$ of responses were on the 'warmer' end of the scale during the heating season compared with only $12 \%$ during the non-heating season. In both seasons, a higher proportion of responses in case study ' $\mathrm{K}$ ' compared to case study ' $\mathrm{N}$ ' were content with their thermal conditions and wanted no change: $49 \%(\mathrm{~K})$ vs. $43 \%(\mathrm{~N})$ during the heating season and $53 \%(\mathrm{~K})$ vs. $48 \%(\mathrm{~N})$ during the non-heating season.

Occupants were asked whether they perceived the air to be fresh or stuffy, on a sevenpoint scale from 1 (fresh) to 7 (stuffy) (Figure 16, right). The mode in both case study workspaces was ' 5 ', with case study ' $N$ ' responses being more skewed towards the 'stuffy' end of the scale than case study 'K's responses. It would be expected that the 
naturally ventilated case study ' $K$ ' would have significant variation in the distribution of responses between the heating and non-heating season, and that the mechanically ventilated case study ' $N$ ' would have little variation between seasons. However, the distribution of responses was almost unchanged in case study ' $\mathrm{K}$ ' during the heating and non-heating seasons, whereas in case study ' $N$ ', the distribution of responses shifted towards the 'stuffy' end of the scale significantly (Table 3 ).
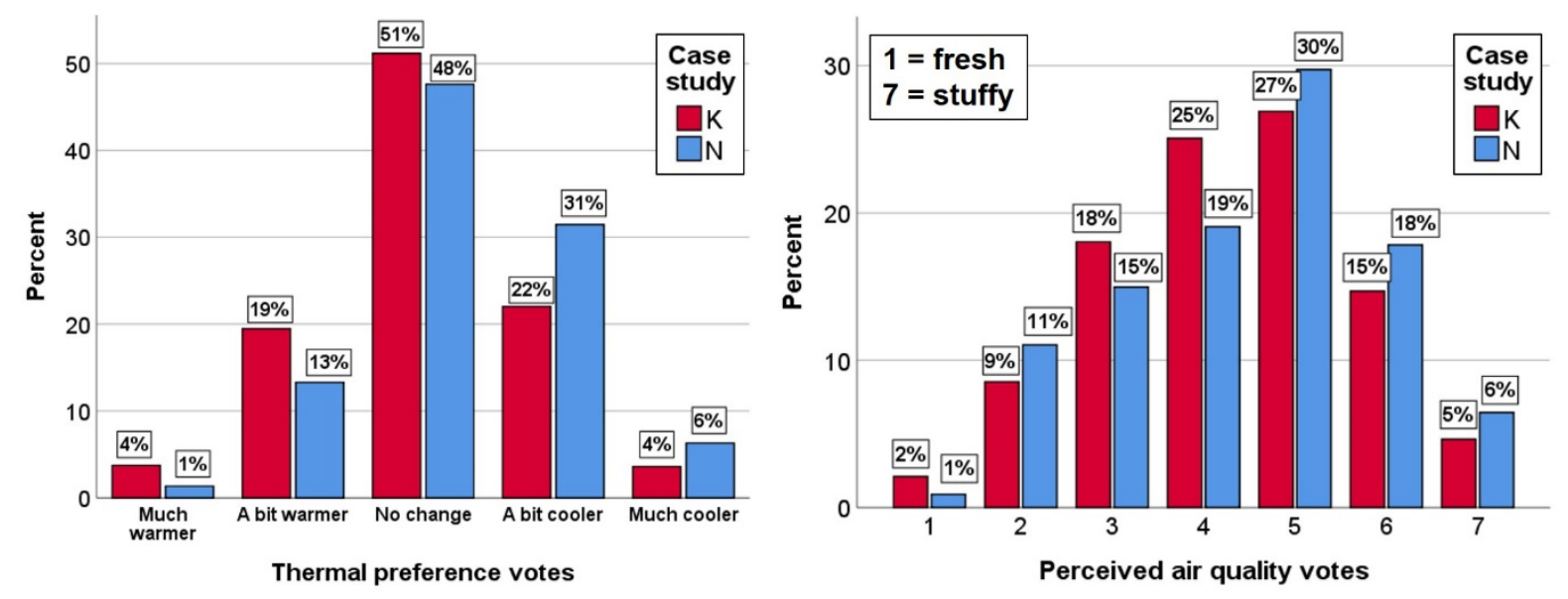

Figure 16 Distribution of thermal preference votes (left) and perceived air quality votes (right) in both case study workspaces.

Table 3 Seasonal variation in air quality votes.

\begin{tabular}{|l|c|c|c|c|}
\hline \multirow{2}{*}{$\begin{array}{c}\text { Air quality } \\
\text { vote }\end{array}$} & \multicolumn{2}{|c|}{ Case study 'K' } & \multicolumn{2}{c|}{ Case study 'N' } \\
\cline { 2 - 5 } & $\begin{array}{c}\text { Heating season } \\
\text { (\%) }\end{array}$ & $\begin{array}{c}\text { Non-heating } \\
\text { season (\%) }\end{array}$ & $\begin{array}{c}\text { Heating season } \\
\text { (\%) }\end{array}$ & $\begin{array}{c}\text { Non-heating } \\
\text { season (\%) }\end{array}$ \\
\hline $\mathbf{1}$ (fresh) & 2 & 2 & 2 & 1 \\
\hline $\mathbf{2}$ & 9 & 8 & 17 & 10 \\
\hline $\mathbf{3}$ & 20 & 17 & 13 & 15 \\
\hline $\mathbf{4}$ & 25 & 25 & 19 & 19 \\
\hline $\mathbf{5}$ & 27 & 27 & 28 & 30 \\
\hline $\mathbf{6}$ & 13 & 16 & 14 & 18 \\
\hline $\mathbf{7}$ (stuffy) & 4 & 5 & 6 & 6 \\
\hline
\end{tabular}

Occupants were asked to rate their overall comfort on a seven-point scale from 1 (unsatisfactory) to 7 (satisfactory) (Figure 17, left). Occupants in case study 'N' were significantly more likley than those in case study ' $\mathrm{K}$ ' to vote at the extreme ends of the scale: $9 \%(\mathrm{~N})$ vs. $5 \%(\mathrm{~K})$ voting $1-2$ (unsatisfactory) and $27 \%(\mathrm{~N})$ vs. $23 \%(\mathrm{~K})$ voting 6-7 (satisfactory).

These survey responses suggest that despite the theoretically more vavourable environmental conditions that were measrured in case study ' $N$ ', at least some of its occupants have more extreme views, or lower tolerance levels when it comes to their comfort within their workspaces. 
The BUS survey question regarding occupant perception of their change in producitviy was adapted for the longitudinal surveys, offering a scale from $-20 \%$ to $+20 \%$ in $5 \%$ increments (Figure 17, right). Around half of responses ( $50 \%$ in ' $\mathrm{K}$ ' and $54 \%$ in ' $\mathrm{N}$ ') were neutral, perceiving no change in their productivity due to their working enviornment. In both case studyies the skew was towards the negative end of the scale: $32 \%$ ('K') and $33 \%$ ('N') perceiving their productivity to be decreased compared to only $19 \%$ ('K') and $12 \%$ ('N') preceiving their producitvity to be increased.
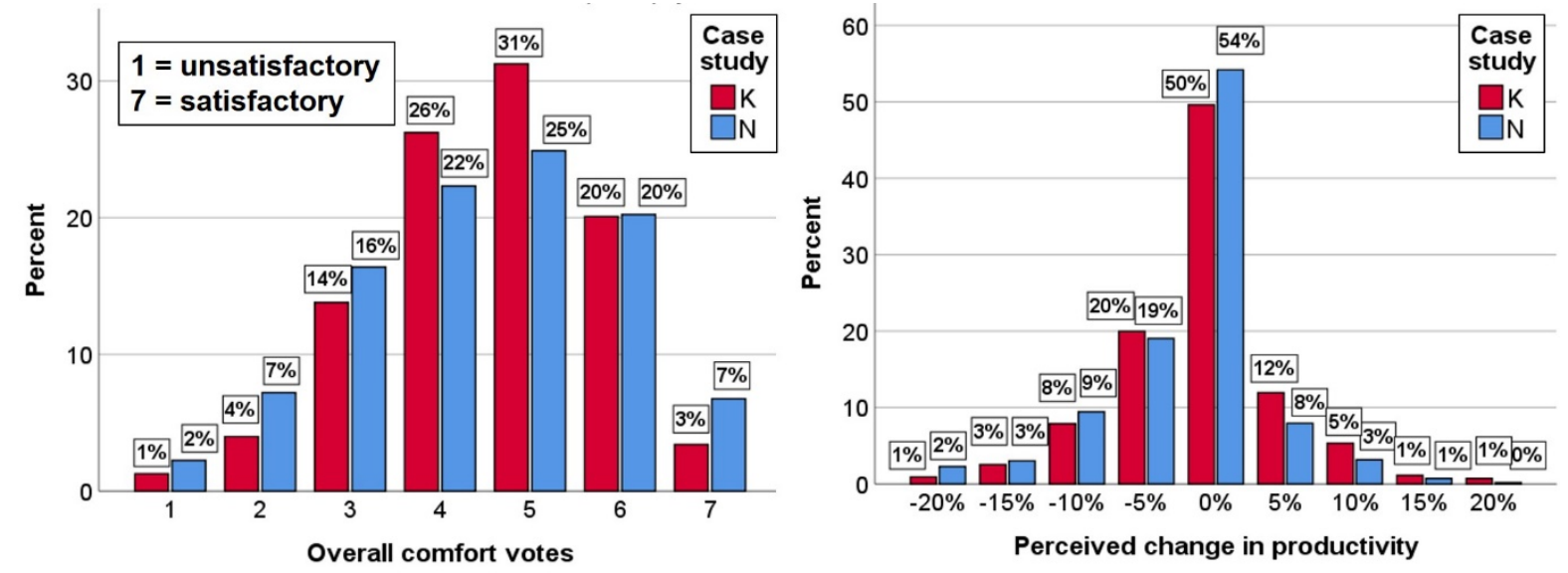

Figure 17 Distribution of overall comfort votes (left) and perceived change in productivity (right) in both case study workspaces.

Responses to different questions could be cross-related to identify correlations and relationships between the two. As with the BUS survey, to do this, the discrete responses were treated as continuous scales, and thermal comfort and preference votes converted to 1-7 and 1-5 scales respectively.

The curvilinear relationships between thermal sensation votes and perceived change in productivity (Figure 18, left) and between thermal preference votes and perceived change in productivity (Figure 18, right) produced trend lines which were very similar in the two case study buildings. In both cases, the further from neutral the votes were, the more respondents felt that their productivity was negatively affected. 

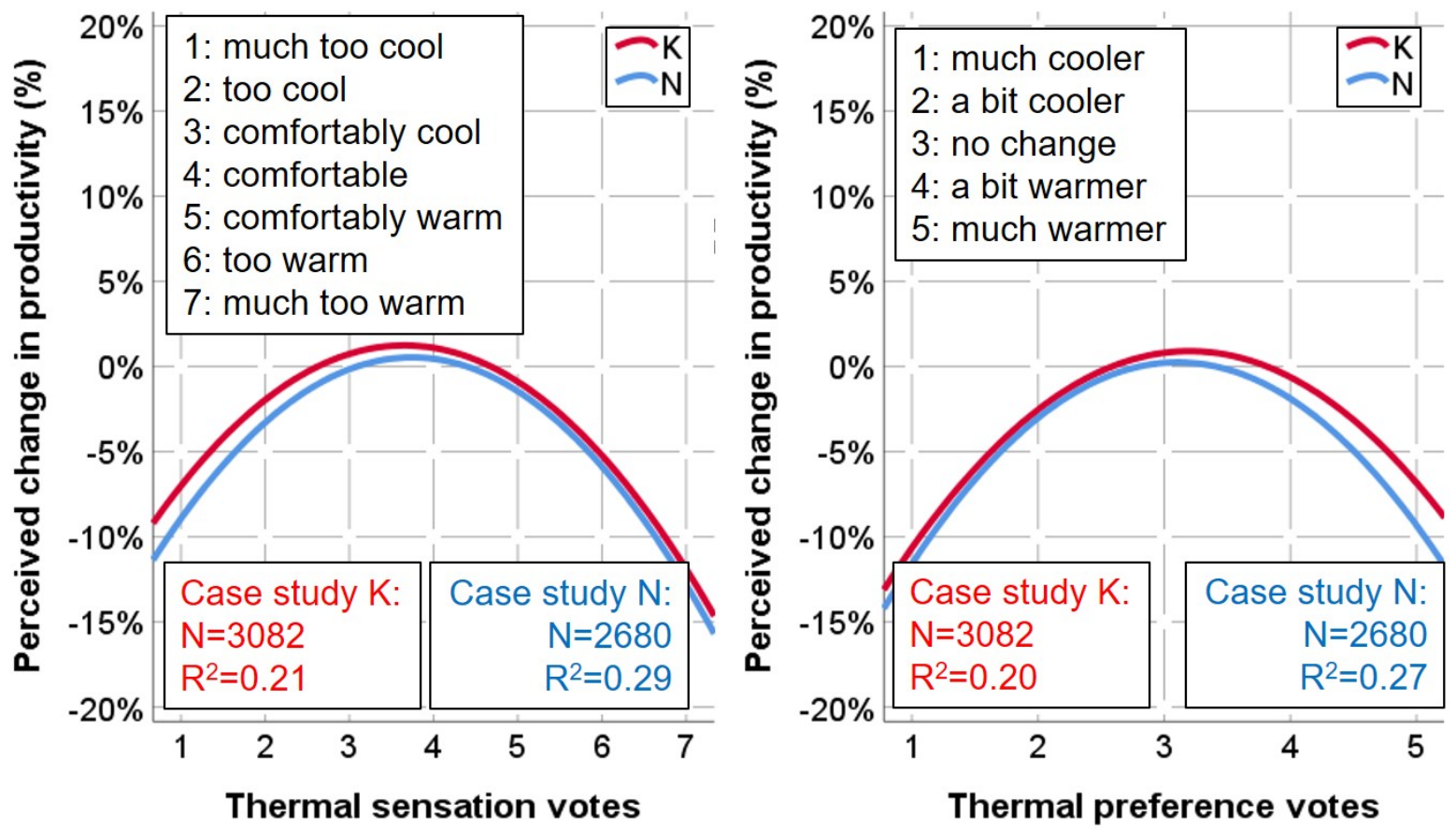

Figure 18 Thermal sensation votes (left) and thermal preference votes (right) plotted against perceived change in productivity in both case study buildings.

The curvilinear relationship between perceived air quality votes and perceived change in productivity (Figure 19, left) produced trend lines for the two case study buildings that were noticeably different. In both case studies buildings, air that was perceived as stuffy correlated with a perceived decrease in productivity. However, in case study ' $\mathrm{K}$ ' responses at the 'fresh' end of the scale correlated with a slightly positive change in productivity, whereas in case study ' $\mathrm{N}$ ', 'fresh' responses correlated with a slight decrease in perceived productivity.

The relationship between overall comfort votes and perceived change in productivity (Figure 19, right) was plotted with a linear trend line since the comfort vote scale went from a negative 'uncomfortable' to a positive 'comfortable', whereas perceived air quality, thermal sensation and thermal preference all have scales from negative to negative, with the neutral/positive response in the middle. Again, the trend lines for the two case study buildings were very similar, with productivity perceived to increase as overall comfort increased. The trend lines indicated that comfort votes of 5-7 correlated with a positive change in productivity, with votes lower than this correlating with a negative change in productivity. 

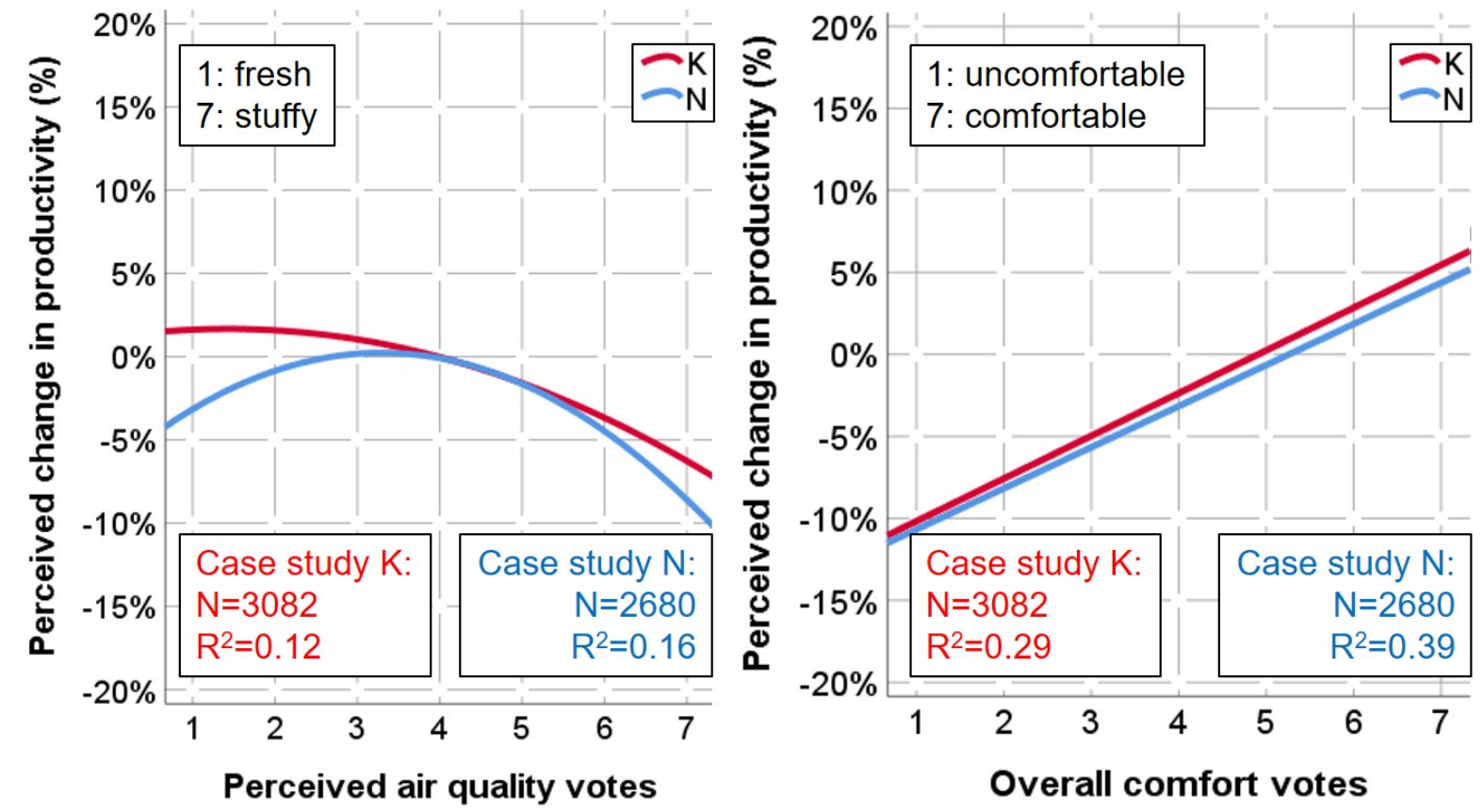

Figure 19 Perceived air quality votes (left) and overall comfort votes (right) plotted against perceived change in productivity in both case study buildings.

A significant finding in all four of the relationships with perceived change in productivity shown in Figure 18 and Figure 19 was that the $\mathrm{R}^{2}$ strength of relationship (indicating the percentage of perceived change in productivity that can be explained by the corresponding variable) is stronger in case study ' $\mathrm{N}$ ' responses than in case study ' $\mathrm{K}$ ' responses. It is also notable that the correlations between perceived change in productivity and the concurrent measured environmental conditions (temperature, $\mathrm{RH}$ and $\mathrm{CO}_{2}$ concentration) were much weaker and not statistically significant.

\section{Measured productivity and indoor environment}

In contrast to the surveys, which indicated the occupants' perception of their working environment and perception of how that affected their productivity, the online tasks were able to provide a proxy measure of productivity in the form of task score and task time. The tasks were location and time stamped so they could be cross-related to the concurrent indoor environmental conditions.

Throughout the study, the Stroop test proved to be the most popular task type, possibly because it took the least time to complete and was the easiest of the three task types. However, this also meant that the test durations were consistently short (the majority taking less than 3 minutes) and test scores were consistently high (the majority scoring $95-100 \%$. This lack of spread of results meant that no meaningful correlations could be found between the Stroop test data and the corresponding indoor environmental conditions. Although less popular, the numerical and proofreading tasks gave wider distributions of test scores and durations.

Plotting test scores (numerical and proofreading) against concurrent indoor temperatures and calculating the corresponding linear trend lines (Figure 20) showed no statistically significant correlation in case study ' $K$ ' - i.e. overall, the respondents' test scores were not affected by the indoor temperatures. However, despite completing their tests within a significantly narrower temperature range, a statistically 
significant Spearman's Rho correlation was found in case study ' $N$ ': $R=-0.22$, significant at the 0.01 level, indicating that test scores decreased at higher temperatures.

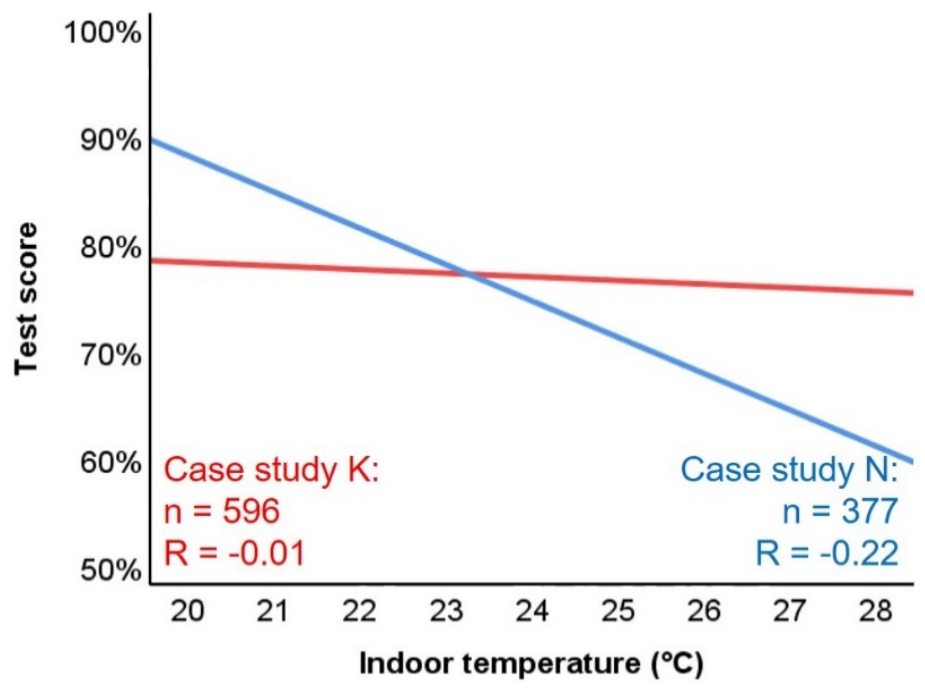

Figure $\mathbf{2 0}$ Indoor temperature vs. test score in both case study buildings.

Grouping the datasets into specific tasks and specific periods, and considering different $\mathrm{CO}_{2}$ concentration thresholds, generated some significant results. In case study ' $\mathrm{K}$ ' during intervention period 1 (March 2018), the distribution of proofreading task scores when $\mathrm{CO}_{2}$ concentrations were below 1400 ppm were significantly higher than when the same tasks were completed at $\mathrm{CO}_{2}$ concentrations above $1400 \mathrm{ppm}$ (Figure 21 (left) and Table 4). Median scores were almost 12\% higher below the 1400 ppm threshold.

During the second intervention period (May/June 2018), the distribution of proofreading task scores when $\mathrm{CO}_{2}$ concentrations were below 1000 ppm were significantly higher than when the same tasks were completed at $\mathrm{CO}_{2}$ concentrations above 1000 ppm (Figure 21 (centre) and Table 4). Median scores were over 4\% higher below the 1000 ppm threshold. Numerical tasks completed during the first intervention period (October/November 2017) had scores 12\% higher (median) when conducted below 1000 ppm compared to above 1000 ppm (Figure 21 (right) and Table 4). Furthermore, these numerical tests took five minutes (mean average) longer to complete at $\mathrm{CO}_{2}$ concentrations above 1000 ppm compared to those conducted below 1000 ppm. 

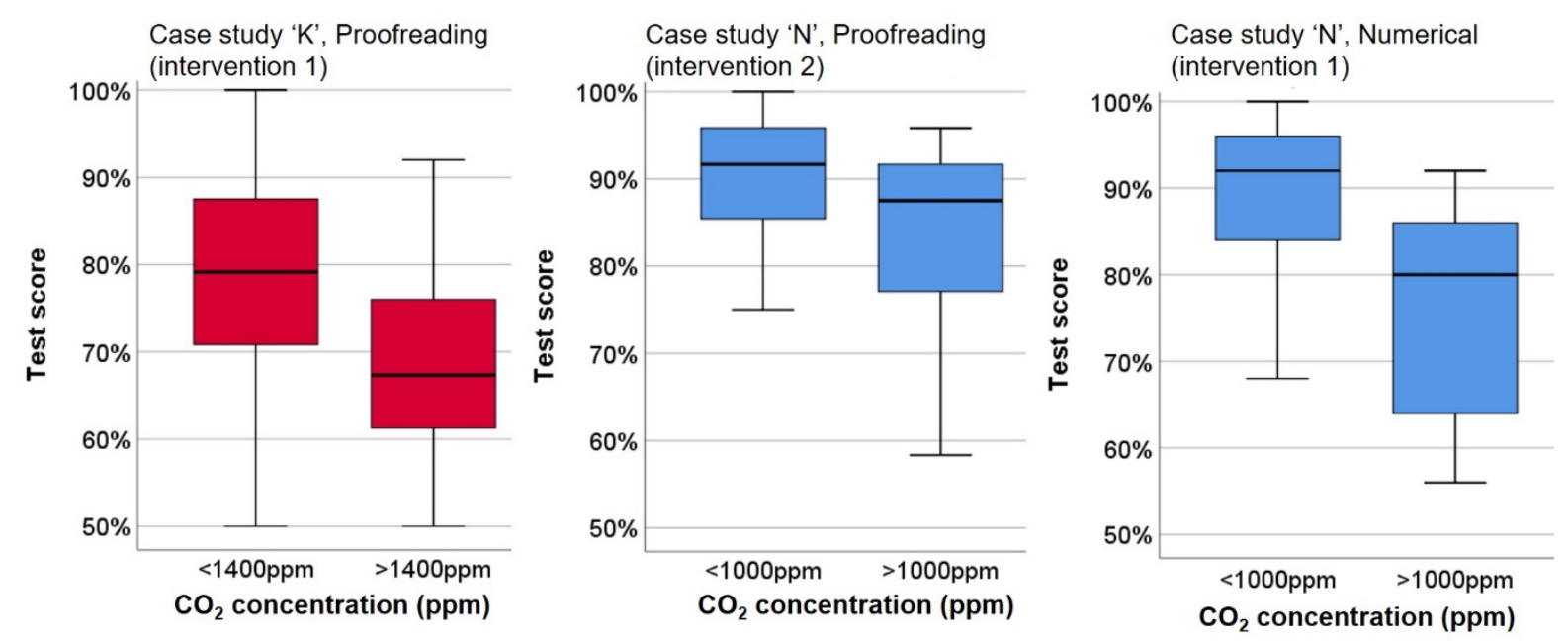

Figure 21 Boxplots showing distribution of test scores above and below $\mathrm{CO}_{2}$ thresholds.

Table 4 Descriptive statistics for selected tasks with selected $\mathrm{CO}_{2}$ thresholds, key statistics highlighted

\begin{tabular}{|c|c|c|c|c|c|c|}
\hline \multirow[t]{2}{*}{ Statistic } & \multicolumn{2}{|c|}{$\begin{array}{l}\text { Case study 'K', } \\
\text { Proofreading, } \\
\text { intervention } 1\end{array}$} & \multicolumn{2}{|c|}{$\begin{array}{l}\text { Case study 'N', } \\
\text { Proofreading, } \\
\text { intervention } 2\end{array}$} & \multicolumn{2}{|c|}{$\begin{array}{l}\text { Case study 'N', } \\
\text { Numerical, } \\
\text { intervention } 1\end{array}$} \\
\hline & $\begin{array}{c}<1400 \\
\text { ppm }\end{array}$ & $\begin{array}{c}>1400 \\
\text { ppm }\end{array}$ & $\begin{array}{c}<1000 \\
\text { ppm }\end{array}$ & $\begin{array}{c}>1000 \\
\text { ppm }\end{array}$ & $\begin{array}{c}<1000 \\
\text { ppm }\end{array}$ & $\begin{array}{c}>1000 \\
\text { ppm }\end{array}$ \\
\hline $\mathrm{N}$ & 77 & 16 & 19 & 20 & 25 & 8 \\
\hline Mean (\%) & 78.3 & 70.0 & 87.9 & 84.0 & 88.0 & 76.0 \\
\hline Median (\%) & 79.2 & 67.3 & 91.7 & 87.5 & 92.0 & 80.0 \\
\hline S.D. (\%) & 12.3 & 11.7 & 13.9 & 10.2 & 14.7 & 13.4 \\
\hline Lower quartile (\%) & 70.8 & 60.6 & 83.3 & 76.0 & 82.0 & 64.0 \\
\hline Upper quartile (\%) & 87.5 & 76.0 & 95.8 & 93.8 & 96.0 & 89.0 \\
\hline
\end{tabular}

Not all of the task types conducted during all of the testing periods produced results that showed significant links to the indoor environment. No statistically significant correlations were found between indoor $\mathrm{RH}$ and either task score or duration, and no temperature thresholds showed significant differences in task score or duration distributions. However, it is interesting that the significant $\mathrm{CO}_{2}$ concentration threshold in case study ' $K$ ' was 1400 ppm, compared to only 1000 ppm in case study ' $N$ '. Indeed, no tasks were completed at $\mathrm{CO}_{2}$ concentrations as high as 1400 in case study ' $\mathrm{N}$ ', and the threshold of $1000 \mathrm{ppm}$ showed no significant differences in task scores or durations in case study ' $\mathrm{K}$ '. This is further evidence that the occupants of case study ' $\mathrm{N}$ ', despite working in less extremes of environment, were more sensitive to their conditions than those in case study ' $\mathrm{K}$ '. 


\section{Discussion}

The study has provided empirical evidence of the links between workplace productivity and the indoor environment, and the contrasting effects of working in a tightly controlled mechanically ventilated building compared to working in a more free running naturally ventilated building.

The environmental monitoring of the two case study workplaces found significant differences in their indoor environmental conditions be it temperature or $\mathrm{CO}_{2}$ levels. Despite this difference, both the transverse and longitudinal surveys showed that occupants in both buildings had similar perceptions of their environments. Indeed, the occupants in case study ' $\mathrm{N}$ ' consistently had higher proportions of votes at the extreme ends of the response scales than their counterparts in case study ' $K$ ', whether that be feeling more or less healthy, more or less satisfied with overall comfort, thermal comfort, thermal preference or perceiving the air to be fresher or stuffier. This suggests that the occupants of case study ' $\mathrm{K}$ ' had learned to adapt to their environment, tolerating higher or lower temperatures, tolerating higher concentrations of $\mathrm{CO}_{2}$, to a significantly greater extent than their case study 'N' counterparts. This supports Geng et al.'s finding that when indoor temperatures were further from the neutral range, occupants had a higher tolerance of other environmental factors (18).

The links between indoor environmental conditions and task performance (as a proxy for productivity) were less strong but nevertheless evident in some tasks. Higher concentrations of $\mathrm{CO}_{2}$ were linked (in some tasks during some periods of time) to lower task scores and longer task durations. The thresholds which most clearly marked these differences were different in the two case study workspaces: $1400 \mathrm{ppm}$ in case study ' $\mathrm{K}$ ' and $1000 \mathrm{ppm}$ in case study ' $\mathrm{N}$ ', again indicative of the adaptive tolerances developed in the occupants of the former. Indoor temperature was found to have a weaker correlation with productivity (both perceived and measured) than the correlation thermal sensation had with perceived productivity. This was in line with Tanabe et al.'s study, which found that actual air temperature was poorly correlated with self-estimated performance, whereas perceived thermal satisfaction correlated well with self-estimated performance.

Perceived productivity (from surveys) and measured productivity (from task performance) were found to offer complementary approaches in defining the link between indoor environment and workplace productivity. Surveys can provide an indication of the links and their relative strength, whereas the tasks may be able to define the thresholds at which productivity begins to be affected.

This study took the approach of involving the entire set of occupants in both case study workspaces, rather than taking a subset of staff members. In doing so, the respondents were self-selecting and, although encouraged to do so, were under no obligation to participate in either the surveys or tasks. As a result, throughout the 19 months of the study, the response rates decreased significantly. Keeping the occupants engaged in the project proved to be a constant challenge.

The study also found that although data sets such as business outputs (calls made and e-mails sent) and HR datasets (absentee rates) could in theory provide valuable measures of productivity, obtaining such data at a resolution high enough to be able to cross relate it to measured indoor environmental conditions can be extremely challenging. Such datasets are likely to be considered sensitive to businesses, and 
their willingness to share them with external parties such as researchers is likely to be limited.

\section{Conclusion}

This paper has presented a systematic data driven approach to empirically investigate the relationship between indoor environment and workspace productivity. By comparing and contrasting results from NV and MV office environments, it is evident that not only can the indoor environment have both a positive and negative impact on perceived and measured productivity, but that the extent of these impacts can depend on the broader environmental conditions experienced by the occupants.

Occupants in the NV case study experienced more extremes of temperature and $\mathrm{CO}_{2}$ concentration than their MV counterparts. However, their survey responses showed that they were more tolerant of these conditions and did not perceive their productivity to be any worse than their mechanically ventilated counterparts. The $\mathrm{CO}_{2}$ thresholds identified at which test scores and durations were decreased were much higher in the NV case study, again indicating that its occupants had adapted to these higher levels.

These findings have important implications for modern industrial practice, especially for optimising the energy and environmental performance of offices. The way that occupants in the NV workspace had adapted to their environment suggests that expending significant amounts of energy to control the indoor environment to within relatively narrow ranges may not be necessary, and may in fact be counterproductive by creating a workforce that is less tolerant of small changes in their environmental conditions. This was evident in the MV case study office, where occupants were significantly less tolerant of small changes to their working environment, resulting in the FM team having to expend more energy in controlling the indoor environment ever more tightly.

The study has also shown that self-reported productivity through transverse and longitudinal surveys can provide meaningful data that is more easily obtainable and arguably at lower cost. In future, such surveys can be deployed in building performance evaluation studies, and also investigations into occupant well-being.

\section{References}

1. BCO. Defining and measuring productivity in offices. London, UK: British Council of Offices; 2017.

2. ONS. International comparisons of UK productivity (ICP), first estimates:

2016. Office for National Statistics; 2017.

3. ONS. Long tem sickness absence UK: Office for National Statistics; 2014

[Available from: https://www.gov.uk/government/statistics/long-term-sicknessabsence.

4. CABE. The impact of office design on business performance. British Council for Offices; 2005.

5. Alker J, Malanca M, Pottage C, O'Brien R. Health, wellbeing \& productivity in offices: The next chapter for green building. World Green Building Council. 2014. 
6. Niemelä R, Hannula M, Rautio S, Reijula K, Railio J. The effect of air temperature on labour productivity in call centres-a case study. Energy and buildings. 2002;34(8):759-64.

7. Seppanen O, Fisk WJ, Lei Q. Effect of temperature on task performance in officeenvironment. Ernest Orlando Lawrence Berkeley NationalLaboratory, Berkeley, CA (US); 2006.

8. Park J, Yoon C. The effects of outdoor air supply rate on work performance during 8-h work period. Indoor Air. 2011;21(4):284-90.

9. Browning B. Biophilia, buildings, and your brain. People and Strategy. 2016;39(2):8.

10. Feige A, Wallbaum H, Janser M, Windlinger L. Impact of sustainable office buildings on occupant's comfort and productivity. Journal of Corporate Real Estate. 2013;15(1):7-34.

11. ASHRAE. Standard 55-2010: Thermal Environmental Conditions for Human Occupancy. Atlanta, GA, USA: ASHRAE; 2010.

12. Witterseh T, Wyon DP, Clausen G. The effects of moderate heat stress and open-plan office noise distraction on SBS symptoms and on the performance of office work. Indoor air. 2004;14:30-40.

13. Lan L, Wargocki P, Wyon DP, Lian Z. Effects of thermal discomfort in an office on perceived air quality, SBS symptoms, physiological responses, and human performance. Indoor air. 2011;21(5):376-90.

14. Vimalanathan $\mathrm{K}, \mathrm{Babu}$ TR. The effect of indoor office environment on the work performance, health and well-being of office workers. Journal of environmental health science and engineering. 2014;12(1):113.

15. Fang L, Wyon DP, Clausen G, Fanger PO. Impact of indoor air temperature and humidity in an office on perceived air quality, SBS symptoms and performance. Indoor air. 2004;14:74-81.

16. Liu J, Yao R, Wang J, Li B. Occupants' behavioural adaptation in workplaces with non-central heating and cooling systems. Applied Thermal Engineering. 2012;35:40-54.

17. Tanabe S-i, Haneda M, Nishihara N. Workplace productivity and individual thermal satisfaction. Building and environment. 2015;91:42-50.

18. Geng Y, Ji W, Lin B, Zhu Y. The impact of thermal environment on occupant IEQ perception and productivity. Building and Environment. 2017;121:158-67.

19. Allen JG, MacNaughton P, Satish U, Santanam S, Vallarino J, Spengler JD. Associations of cognitive function scores with carbon dioxide, ventilation, and volatile organic compound exposures in office workers: a controlled exposure study of green and conventional office environments. Environmental health perspectives.

2015;124(6):805-12.

20. Chang TY, Kajackaite A. Battle for the thermostat: Gender and the effect of temperature on cognitive performance. PloS one. 2019;14(5):e0216362.

21. Tham K, Willem H. SYMPOSIUM PAPERS-DE-05-10 Indoor Environments and Human Productivity-Temperature and Ventilation Effects on Performance and Neurobehavioral-Related Symptoms of Tropically Acclimatized Call Center.

ASHRAE Transactions-American Society of Heating Refrigerating Airconditioning Engin. 2005;111(2):687-98.

22. Wargocki $\mathrm{P}$, Wyon DP, Fanger PO. Pollution source control and ventilation improve health, comfort and productivity. DKV TAGUNGSBERICHT. 2000;27(4):4754. 
23. Satish U, Mendell MJ, Shekhar K, Hotchi T, Sullivan D, Streufert S, et al. Is $\mathrm{CO} 2$ an indoor pollutant? Direct effects of low-to-moderate CO2 concentrations on human decision-making performance. Environmental health perspectives. 2012;120(12):1671-7.

24. Kajtar L, Herczeg L, Lang E, editors. Examination of influence of CO2 concentration by scientific methods in the laboratory. Proceedings of healthy buildings; 2003.

25. Fisk WJ, Price P, Faulkner D, Sullivan D, Dibartolomeo D, Federspiel C, et al. Worker performance and ventilation: analyses of time-series data for a group of callcenter workers. 2002.

26. Mulville M, Callaghan N, Isaac D. The impact of the ambient environment and building configuration on occupant productivity in open-plan commercial offices. Journal of Corporate Real Estate. 2016;18(3):180-93.

27. Lipczynska A, Schiavon S, Graham LT. Thermal comfort and self-reported productivity in an office with ceiling fans in the tropics. Building and Environment. 2018;135:202-12.

28. Al Horr Y, Arif M, Kaushik A, Mazroei A, Katafygiotou M, Elsarrag E. Occupant productivity and office indoor environment quality: A review of the literature. Building and environment. 2016;105:369-89.

29. Gupta R, Cudmore T, Bruce-Konuah A. Desktop investigation to examine the relationship between indoor environmental conditions and productivity in work spaces. Investigating market demand and supply of construction industry waste as. 2016:207.

30. BUS. BUS methodology [Available from: http://www.busmethodology.org.uk

\section{Figures}

Figure 1 The two case study buildings: Case study 'K' (left) and case study 'N' (right) ......... 5

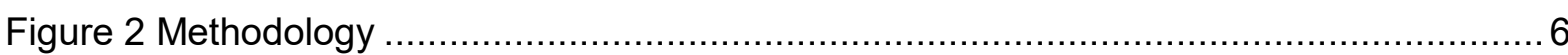

Figure 3 Hourly average working hours indoor temperatures (Mar 2017 - Sep 2018) (left) and descriptive statistics for the heating and non-heating seasons in both case study buildings (right) 9

Figure 4 Boxplot showing monthly distribution of indoor temperatures during working hours in the two case-study workspaces, with line plots showing monthly average outdoor temperatures at the two sites.

Figure 5 Diurnal indoor temperature profiles for sample heating season month (February 2018) and non-heating season month (July 2017) in both case studies.

Figure 6 Working hours indoor $\mathrm{CO}_{2}$ concentration (Mar 2017 - Sep 2018) (left) and descriptive statistics for the heating and non-heating seasons in both case study buildings (right)...... 11

Figure 7 Boxplot showing monthly distribution of indoor $\mathrm{CO}_{2}$ concentrations during working hours in the two case-study workspaces.

Figure 8 Average $\mathrm{CO}_{2}$ concentration in case studies $\mathrm{K}$ and $\mathrm{N}$ (indoor and outdoor) during sample months (Feb 2018, left, and Jul 2017, right).

Figure 9 Working hours indoor RH (Mar 2017 - Sep 2018) (left) and descriptive statistics for the heating and non-heating seasons in both case study buildings (right).

Figure 10 Boxplot showing monthly distribution of indoor $\mathrm{RH}$ during working hours in the two case-study workspaces, with line plots showing monthly average outdoor $\mathrm{RH}$ at the two sites. 
Figure 11 Average $\mathrm{RH}$ in case studies $\mathrm{K}$ and $\mathrm{N}$ (indoor and outdoor) during sample months

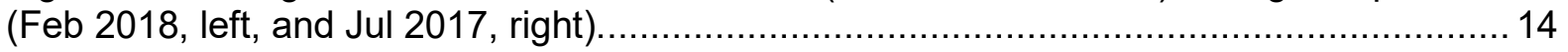

Figure 12 Distribution of overall comfort votes (left) and perceived change in health (right) for both case study buildings

Figure 13 Distribution of responses to perceived change in productivity for both case study buildings. 16

Figure 14 Relationship of overall comfort votes (left) and perceived change in health (right) with perceived change in productivity for both case study buildings.

Figure 15 Distribution of thermal comfort votes in both case study workspaces. 18

Figure 16 Distribution of thermal preference votes (left) and perceived air quality votes (right) in both case study workspaces.

Figure 17 Distribution of overall comfort votes (left) and perceived change in productivity (right) in both case study workspaces.

Figure 18 Thermal sensation votes (left) and thermal preference votes (right) plotted against perceived change in productivity in both case study buildings.

Figure 19 Perceived air quality votes (left) and overall comfort votes (right) plotted against perceived change in productivity in both case study buildings.

Figure 20 Indoor temperature vs. test score in both case study buildings. 23

Figure 21 Boxplots showing distribution of test scores above and below $\mathrm{CO}_{2}$ thresholds.... 24 